\title{
Comparative analysis of apricot cultivars based on their ecological and biological indicators
}

\author{
Surányi, D. \\ Fruit Research Station, Cegléd H- 2700, P O Box 33.
}

\begin{abstract}
Summary: The herbaceous plants organic characterize Ellenberg et al. worked out (1991), well-use system, which is updated with herbaceous and woody plant in the Hungarian flora species, so Soó (1964-1985), Zólyomi et al. (1967), Précsényi (1986) and Simon (1988) also addressed by different aspects of this problem circuits. The author is the first extended-Borhidi -Ellenberg's system of wild fruit species (Surányi 2000, 2006) and cultivated of fruit (Surányi 2014) as well. Additional considerations there were aspects of the study of fruit varieties, these biological indicators following open pollination, frost tolerance, resistance of Sharka virus and disease susceptibility for. Firstly, we introduced a system for improving it a plum species and cultivars (Surányi 2015). In this case we used the new system among species and varieties of apricots, because diversity was able to express significantly. Especially the SB, WB, NB, and the relative biological value figures showed the variety. RB (reaction figures) fluctuated only slightly among the 463 varieties, but the dynamic difference between the 11 's was an indicator for the characterization of apricots. If the comparison performed plum and apricot variety's level anyway justified the use of 11 kinds of organic and biological indicators.
\end{abstract}

Keywords: apricot cultivars, relative ecological and biological figures, comparative studies of cultivars

\section{Introduction}

Most apricot varieties developed in the Armeniaca vulgaris wild forms, natural shapes $1500-2000 \mathrm{~m}$ can be found in China and Central Asia, mountains nature (Löschnig - Passecker 1954, Larcher 1980, Nyujtó - Surányi 1981, Faust - Surányi 1988). The Siberian apricot (A. sibirica) has high frost resistance (Kosztina 1936, 1964, Nyujtó - Surányi 1981), like the Manchurian apricot (A. mandschurica); however, the Japanese (A. mume) and Korean apricots $(A$. ansu) are hotter consuming and also water-demanding (Kosztina 1936, Nyujtó - Surányi 1981, Surányi 2011). The black (A. x dasycarpa) and white apricot (A. leiocarpa) species hybrids weakly fertile them and resist diseases (Kosztina 1936, Löschnig - Passecker 1954, Nyujtó Tomcsányi 1959). Other so-called small species hardly play a role in the creation of the varieties grown today (briançon and Tibetan apricot) (Terpó 1974, Faust et al. 2011).

Where rainfall average temperature and $400 \mathrm{~mm}$ per year around $9^{\circ} \mathrm{C}$ around, there is the most growing districts, A. vulgaris can be grown, but are known extreme favored areas (Dzhungaria, Manchuria, Tibet, Hunza Valley) found (Crossa-Raynaud 1977, Nyujtó - Surányi 1981 and Surányi 2011). Indeed, certain types of cultivated live taxon may outlet (salt), desert areas, or wherein the annual average temperature of $12-13^{\circ} \mathrm{C}$, and only $50 \mathrm{~mm}$ rainfall (Mehlenberger et al. 1992, Faust - Surányi 1998).

The Armeniaca genus species of types of light-intensive, Odier (1978), the role of light - according to latitude - is well demonstrated in the row and plant spacing changing what it proved ingenious experiment provider (1981) (see Nyujtó
- Surányi, 1981). Apricot moderate water demand, it will benefit watering, especially prior to maturity, but all kinds of species prefer soils in the air.

A wild apricot rootstock (as Armeniaca vulgaris convar. minor) subject especially harmful to the groundwater level is high. According Kosztina (1936) and Löschnig Passecker (1954), the best varieties like the sandy, rocky, clay soil subsoil and the deep layers of clay and light loess soils. Neutral or slightly alkaline soils are best suited for the apricot (see Surányi 2011). Too much lime and soda negative content; varieties of Central Asian origin, more tolerant.

One species of wild apricot not indigenous to the Carpathian Basin, although many of the old Hungarian varieties can be escape (forests, cultivated fruit and vine landscape etc.).

The introduction several historical concepts, the wild apricot presumably over the exodus appeared - at today's Ukraine. The "real apricot" (as Turkish kāyst) naturalized during the Turkish occupation it was first around town in Tolna (after 1541, Surányi 2011), and began to cultivate it and Kecskemét and Gönc areas. There are Hungary almost exclusively grown varieties in Armeniaca vulgaris and grown. However, the study provides information on the types of Armeniaca genus known worldwide ecological and biological value of the relative indicators.

The origin of species, their genetic and biological properties of the characters assume the specific ecological needs (Faust - Surányi 1998). In a number of branches of botany ecological evaluation is not new, examples of which can be found in the literature on Hungarian language (Soó 1964-1985, Zólyomi 1964, Kárpáti Z. - Terpó 1971, Kárpáti 
I. 1978, Précsényi 1986, Simon 1988 and Borhidi 1993). Over the last decade, based mainly on works of Simon (1988, 1991) and Kovács (1979), individual ecological indicator values have been established (Surányi 2000, 2002, 2006, 2009), and applied for the varieties prepared in the national cultivar catalogue (Pernesz 2016), pomological handbooks (Soltész 1998) and former historic ecological works (cf. Surányi 2002). This study presents an expanded and updated version of that one published in Kanitzia (Surányi 2006), and a summary of Hungarian fruit cultivars in Acta Bot. Hung. (Surányi 2014), towards for plum cultivars (Surányi 2015).

There were suitable for comparing the apricot cultivars and wild forms based on 463 relative ecological figures (cf. Borhidi 1995), towards also a large number of data and its own observations, the relative biological indices. Since studies - in particular increased numbers can be expressed in value relative ecological figures of importance: due to climate change because of the extreme weather, billowy period of rainfall actual vegetation, mostly drought tolerant apricots and role increase. Climate change impacts not only effects because of pathogens (virus, bacteria and other complex disease as apoplexy and phytoplasma).

Although it is very difficult to prove the following relevantly, but experience shows that the largest number of cultivars can change your reaction on the environment (cf. Larcher 1980). So that no less - and therefore for this reason - the physiognomic character of apricots too. Increasingly drier due the weather due to the increasing weight vector organisms (aphids, cicadas) cause problems of the viral disease, or wet vegetation - and of myrobalan rootstock scions - towards fungal problems.

In the preface ecological requirements of Armeniaca species which can be found in the literature (Kosztina 1936, Iversenn 1936, Löschnig - Passecker 1954 Mehlenberger et al. 1991, Cociu 1993 and Faust - Surányi 1998). Especially TB and WB showed the most is that the species is used which taxon. This seems quite certain, although about $90 \%$ of the Armeniaca vulagaris to the varieties of exemplary subject. It was even more conclusive, after the introduction of the relative biological indicators (Surányi 2015), which these data define the use of apricots grown varieties.

The apricot varieties, wild shapes and new hybrid varieties appear to have a narrow genetic diversity and pomological as a taxonomically variety of plum cultivars. Namely accordance with Table 1 shows that the relative indicators affected 2-3 categories. In the case of SB tight until the interval affects 21 cultivars (4,5\% of the total), these Central Asian or desert derived cultivars (Kosztina 1936 and 1964, Tomcsányi 1960 and 1979, Löschnig - Passecker 1954, Nyujtó - Tomcsányi 1959).

Relative ecological indicators of Ellenberg et al. (1991) and Borhidi (1969 and 1995) were valid in species level, although the same show greater volatility than the survey cultivars of Armeniaca genus, but the differences are smaller and linked dynamically changed.

Finally, Table 3 also confirms that the 11 different indicators on plums (Surányi 2015) and in this case - is used to express the differences between the varieties of apricot; compared to the average values are generally significantly between the two fruit species. Probably use of organic and biological indicators can be differentiated analysis of other stone fruit species (see Faust 1989).

\section{Materials and methods}

There are 463 different cultivated and old apricot cultivars which have different taxonomic and ecological character in Material and Methods. These relative values determined on the basis of the ecological information of apricots for references to main literary sources (Tüxen - Ellenberg 1937, Ellenberg et al. 1991). The definition of Borhidi's ecological figures is following (Borhidi 1995).

TB: The relative temperature figures reflecting the heat supply of the habitats where the species occur (mainly based on the distribution according to the latitudinal vegetation zones and altitudinal belts). The temperature figures of Ellenberg's (1952 and 1974) 9-grade scale (T) applied by Borhidi (B) (1995) to the Hungarian flora by Surányi (2014) and plum cultivars by Surányi (2015) to the Hungarian culture's flora. The relative figures indicate the following heat-climate belts or the corresponding microclimate conditions:

5. Montane mesophilous broad-leaved forest belt

6. Submontane broad leaved forest belt

7. Thermophilous forest or woodland belt

8. Submediterranean woodland and grassland belt.

WB: The relative moisture figures (occurrence in relation to soil moisture or water table) according to the 12-grade F-scale of Ellenberg (1963). The scale is very similar to the W-scale of Zólyomi (1964), but the water plants have a more detailed categorization, as follows:

3. Xero-tolerants, but eventually occurring on fresh soils

4. Plants of semidry habitats

5. Plants of semi humid habitats, under intermediate conditions.

RB: Reaction figures, according to the nine-grade Ellenberg's scale (1952), reflect to the occurrence of the plants in relation of the soil reaction of the habitats (Tüxen - Ellenberg 1937). In the 5-grade Zólyomi's (1987) scale calciphilous and salt tolerant or even halophilous plants are equally treated as basiphilous plants. Here the two groups are differentiated by their positive or negative salt figure category. A comparison of the reaction value scales according to Ellenberg's (1952) versus Zólyomi's classification (1987) was carried out by Pichler-Karrer (1991). The correspondent degrees are:

5. Plants of slightly acid soils

6. Mostly on neutral soils but also in acid and basic ones, generally widely tolerant, more or less indifferent plants

7. Basifrequent plants, mostly on basic soils.

NB: Nitrogen figures according to Ellenberg's 9-grade scale (1974), based on the occurrence in relation to the 
ammonia and nitrate supply of the habitats, which received Borhidi (1995) then Surányi (2014 and 2015) too. These are degrees:

4. Plants of submesotrophic habitats

5. Plants of mesotrophic habitats

6. Plant of moderately nutrient rich habitats.

LB: Light figures according to Ellenberg's 9-grade scale (1974), based on the occurrence of plants in relation to relative light intensity during summer time. Degrees are follows:

7. Half light plants, mostly living in full light but also shadow tolerant

8. Light plants; photosynthetic minimum above $40 \%$ relative light intensity, less only in exceptional cases

9. Full light plants of open habitats not receiving less than $50 \%$ of relative light intensity.

KB: Continentality values according to Ellenberg's ninegrade scale (1950 and 1952) based on the main distribution of plants according to degree of continentality of the general climate (see Meusel - Schubert 1972) with emphasis on maximum and minimum temperature. Degrees following:

5. Intermediate type with slight suboceanic-subcontinental character

6. Subcontinental, main area in eastern Central Europe

7. Continental-subcontinental species main area in EastEurope

8. Continental species reaching only eastern part of Central Europe.

SB: Salt figures for indicating plant occurrence in relation to the salt concentration of the soils in a 9-grade scale, according to Scherfose (1990). Literary sources of ecological indicators are included in the Introduction, because breakdown by type of detail is not possible. The salt figures at least, developed to the SB. The toxic salt content is generally perceived afterwards, when the trees have been damaged:

0 . Halophob species not occurring in salty or alkalic soils

1. Salt tolerant plants but living mainly on non-saline soils.

It was developing new added relative value numbers that have been introduced in the fruit-bearing species. We first presented in open pollination, the flower buds and bark frost sensitivity and significance for cultivated and wild apricots main concern viruses Sharka sensitivity and susceptibility to disease pathology (monilia, fusicladium, apoplectic and phytoplasmatic causes) characterization among the apricot cultivars. The first definitions are related to the plum an prune paper (Surányi 2015).

$\mathbf{O P}=$ Measuring of open pollination

1. over $35 \%$ of open pollination

2. $20-35 \%$ of open pollination

3. $2-20 \%$ of open pollination

4. below $2 \%$ of open pollination.

$\mathbf{F R}=$ Degree of frost resistance

1. frost tolerant (over $5 \%$ of flower bud and bark damage)

2. moderately frost sensitive (15-40\% of damages)

3 . frost sensitive (about $50 \%$ of frost damages).
$\mathbf{S S}=$ Relative value of Sharka virus sensitivity

1. resistant to Sharka ( $0=$ no symptoms and presence)

2. tolerant to Sharka (no symptoms, or only in the leaves)

3. susceptible (largely symptomatic leaves and fruits)

4. very sensitive (symptomatic of the whole tree).

$\mathbf{D R}=$ Measuring of disease resistance

1. resistant to disease $(0=$ no symptoms on the trees $)$

2. moderately sensitive (cc. $30 \%$ of leaves or fruit symptoms)

3. sensitive (over $50 \%$ of leaf symptoms and fruit falling).

In this study we wanted to choose, whether it is possible in an different species, though several taxa botanical species and under species the representatives of the ecological and biological differences between cultivars characterization according to Ellenberg - Borhidi - Surányi’s modified based on the relative figures. The results are shown in summing Table 1-3; assuming that the cultivars will be easier of origin and economic-botanical view can be evaluated, increasing the effectiveness of apricot growing.

The relative ecological and biological indicators conducted a wide range of rated apricot cultivars. The types of properties, characteristics of the data collected in these funds, which supplemented their observations by certain varieties and hybrids (Surányi 1991-2015). Because of the large number of types of data links one by one, we have not done, the resources used were as follows: Bordeianu et al. (1967 and 1969), Brook - Olmo (1972), Brózik (1960), Brózik - Nyéki (1975), Cociu (1993), Crane - Lawrence (1956), Entz (1857-1859), Faust et al 2011, Faust - Surányi (1998), Fideghelli - Monstra (1977), Gardner et al. (1952), G. Tóth (1997), Gyuró (1974 and 1990), Hedrick (1938), Iszakova (1988), Jávorka - Soó (1951), Knight (1969), Kobel (1954), Kosztina (1936), Kosztina (1936), Kozma et al. (2003), Krüssmann (1978), Löschnig - Passecker (1954), Mándy (1963), Martinez-Gomez (2000), McGregor (1976), Mehlenberger et al. (1991), Nyéki (1980), Nyéki - Soltész (1996), Nyéki - Soltész - Szabó (2012), Nyujtó - Surányi (1981), Papp (2003 and 2004), Papp -Tamási (1979), Pénzes - Szalay (2004), Pernesz (2016), Porpáczy (1964), Roach 1985, Schwanitz 1973, Soltész (1998 and 2014), Soriano et al. (2008), Surányi (1985 and 2011), Szalay - Surányi - †Nyujtó (2011), Szmükov (1974), Tomcsányi (1960 and 1979) V. Németh (1986) and Zhebentyeyeva et al. (2008).

\section{Results and discussion}

There were suitable for comparing the apricot cultivars and wild forms based on 463 relative ecological figures (cf. Borhidi 1995), towards also a large number of data and its own observations, the relative biological indices. Since studies - in particular increased numbers can be expressed in value relative ecological figures of importance: due to climate change because of the extreme weather, billowy period of rainfall actual vegetation, mostly drought tolerant 
apricots and role increase. Climate change impacts not only effects because of pathogens (virus, bacteria and other complex disease as apoplexy and phytoplasma).

Although it is very difficult to prove the following relevantly, but experience shows that the largest number of cultivars can change your reaction on the environment. So that no less - and therefore for this reason - the physiognomic character of apricots too. Increasingly drier due the weather due to the increasing weight vector organisms (aphids, cicadas) cause problems of the viral disease, or wet vegetation - and of myrobalan rootstock scions - towards fungal problems (Table 1).

In the preface ecological requirements of Armeniaca species which can be found in the literature (Kosztina 1936, Löschnig - Passecker 1954 Mehlenberger et al. 1991, Cociu 1993 and Faust - Surányi 1998). Especially TB and WB showed the most is that the species is used which taxon. This seems quite certain, although about $90 \%$ of the Armeniaca vulagaris to the varieties of exemplary subject. It was even more conclusive, after the introduction of the relative biological indicators (Surányi 2015), which these data define the use of apricots grown varieties.

Summing up the results in Table 1, it was found that most of the varieties were different salt resistance $(\mathrm{CV}=135,3 \%)$, but according to the relative average variability of biological indicators varieties are not much higher than $30 \%$ (cf. Table 2). According to the RB and LB of apricots least it appears to be specific, so it important consideration when selecting optimal phytotechnical methods for apricot varieties. If the growers had no experience in accordance with the indicator is presented in Table 1, assume that two reasons: the data related to available own root (seedling and vegetative propagated plant), or wild apricot rootstock seedlings. An exception was the cherry plum $\mathrm{x}$ apricot hybrids - myrobalan subjects (as myrobalan apricot C. 308, Black apricot etc.) (Table 2).
Earlier studies have been faced with these difficulties (Surányi 2000, 2006, 2014 and 2015). Still, there are several ways we tried to evaluate the fruit species, that is not only used in Ellenberg and Borhidi's figures, but Soó (1964-1985), Zólyomi et al. (1967), Simon (1988 and 1991) and Kovács (1979) also tried to evaluate the concept of fruit growing (that is in our fruit flora) cultivars. Although the literature cited authors examined all the natural species, varieties produced also tried to extend it. Finally, the Borhidi's relative ecological indicators found to be satisfactory analysis of the varieties (Surányi 2006, 2014 and 2015) (Table 1 and 2), which extended its biological figures.

The apricot varieties, wild shapes and new hybrid varieties appear to have a narrow genetic diversity and pomological as a taxonomically variety of plum cultivars. Namely accordance with Table 1 shows that the relative indicators affected 2-3 categories. In the case of SB tight until the interval affects 21 cultivars $(4,5 \%$ of the total), these Central Asian or desert derived cultivars (Kosztina 1936, Tomcsányi 1960, Löschnig - Passecker 1954, Nyujtó - Tomcsányi 1959).

Relative ecological indicators of Ellenberg et al. (1991) and Borhidi (1995) were valid in species level, although the same show greater volatility than the survey cultivars of Armeniaca genus, but the differences are smaller and linked dynamically changed.

Finally, Table 3 also confirms that the 11 different indicators on plums (Surányi 2015) and in this case - is used to express the differences between the varieties of apricot; compared to the average values are generally significantly between the two fruit species. Probably use of organic and biological indicators can be differentiated analysis of other stone fruit species Table 3).

Table 1: Relative ecological and biological indicator values of apricot cultivars

\begin{tabular}{|l|c|c|c|c|c|c|c|c|c|c|c|}
\hline \multicolumn{1}{|c|}{ Cultivar } & TB & WB & RB & NB & LB & KB & SB & OP & FR & SS & DR \\
\hline $86 / 36 / 7 / 8$ & $6-7$ & $3-4$ & 6 & $4-5$ & 7 & $5-6$ & 0 & $2-3$ & 2 & $1-2$ & $1-2$ \\
\hline $5212 / 5 / 8$ & $6-7$ & $3-4$ & 6 & $4-5$ & 7 & 6 & 0 & $1-2$ & $1-2$ & 2 & 1 \\
\hline $597 / 19$ & $6-7$ & $3-4$ & 6 & $4-5$ & $7-8$ & $6-6$ & 0 & 2 & 2 & $1-2$ & 2 \\
\hline $64 / 123 / 7$ & 6 & 3 & 6 & $4-5$ & 7 & 6 & 0 & $2-3$ & 2 & 2 & 2 \\
\hline $644 / 1$ & $6-7$ & $3-4$ & 6 & $4-5$ & $7-8$ & 6 & 0 & $1-2$ & 2 & $1-2$ & $1-2$ \\
\hline $1553 / 54$ & $6-7$ & $3-4$ & 6 & $4-5$ & 7 & 6 & 0 & 2 & 2 & 1 & 1 \\
\hline Abelardo & 7 & 3 & 6 & 5 & 8 & 7 & 0 & 2 & 3 & 2 & 2 \\
\hline Abutalibi & 7 & 3 & $6-7$ & 5 & 8 & $6-7$ & 0 & $1-2$ & 1 & $1-2$ & 1 \\
\hline Agdzsanabad & 7 & 3 & $6-7$ & 5 & $7-8$ & 6 & $0-1$ & 2 & 2 & 2 & 2 \\
\hline Ahrori & $6-7$ & $3-4$ & $6-7$ & 5 & $7-8$ & 6 & 0 & 2 & 1 & $1-2$ & $1-2$ \\
\hline Ahverdi & 7 & $3-4$ & 6 & 5 & $7-8$ & $7-8$ & 0 & 2 & 2 & 2 & 1 \\
\hline Aldin-psar & 7 & 3 & $6-7$ & 5 & $8-9$ & 7 & 0 & 2 & 2 & 2 & $1-2$ \\
\hline Alekszander Nikitszkij & $6-7$ & $3-4$ & 6 & $4-5$ & $7-8$ & 7 & 0 & 2 & 2 & 2 & $1-2$ \\
\hline Alex & $6-7$ & $3-4$ & 6 & $4-5$ & 7 & 7 & 0 & $2-3$ & $2-3$ & 2 & 2 \\
\hline Alexandriai fekete & 7 & 3 & 7 & 5 & 8 & $7-8$ & $0-1$ & 2 & 2 & $1-2$ & $1-2$ \\
\hline Alfred & 6 & $3-4$ & 6 & $5-6$ & 7 & $6-7$ & 0 & 2 & 2 & 2 & 2 \\
\hline
\end{tabular}




\begin{tabular}{|c|c|c|c|c|c|c|c|c|c|c|c|}
\hline Cultivar & $\mathrm{TB}$ & WB & $\mathrm{RB}$ & NB & LB & KB & SB & $\mathrm{OP}$ & $\mathrm{FR}$ & SS & DR \\
\hline Alma-Atinszkij & $6-7$ & 3 & 6 & 5 & $7-8$ & $7-8$ & 0 & 2 & $1-2$ & $1-2$ & $1-2$ \\
\hline Alte Ananas & $6-7$ & $3-4$ & $6-7$ & $4-5$ & 7 & 7 & 0 & 2 & 2 & 2 & 2 \\
\hline Alves & $6-7$ & 4 & $6-7$ & $4-5$ & 8 & 7 & 0 & $1-2$ & 2 & $1-2$ & $1-2$ \\
\hline Alyanak & $7-8$ & 3 & $5-6$ & 5 & $7-8$ & 8 & 0 & 2 & 2 & 2 & 2 \\
\hline Ambrózia & $6-7$ & $3-4$ & $6-7$ & 4 & $7-8$ & $5-6$ & 0 & 2 & 2 & 2 & 3 \\
\hline Ananász & $6-7$ & 3 & $6-7$ & $4-5$ & 7 & 7 & 0 & 3 & 2 & 2 & 3 \\
\hline Anda & $6-7$ & 4 & 6 & $5-6$ & 7 & 7 & 0 & 2 & 1 & 1 & 1 \\
\hline $\begin{array}{l}\text { Andornaktályai Magyar } \\
\text { kajszi }\end{array}$ & $6-7$ & $3-4$ & $6-7$ & $4-5$ & $7-8$ & 7 & 0 & 2 & $1-2$ & 2 & $2-3$ \\
\hline Angoumois & $6-7$ & $3-4$ & 6 & $5-6$ & $7-8$ & $6-7$ & 0 & $2-3$ & $1-2$ & 2 & 2 \\
\hline Anhan & 7 & $3-4$ & $6-7$ & 5 & $8-9$ & $7-8$ & 0 & $1-2$ & $2-3$ & $1-2$ & 2 \\
\hline Arab kajszi & $7-8$ & 3 & 7 & $4-5$ & 8 & 8 & $0-1$ & 2 & 3 & 2 & 1 \\
\hline Arzami & $6-7$ & $3-4$ & 6 & 5 & $7-8$ & $5-6$ & 0 & $1-2$ & $1-2$ & 1 & 2 \\
\hline Aurora & $6-7$ & $3-4$ & 7 & $4-5$ & $7-8$ & 7 & 0 & $1-2$ & 2 & 2 & 2 \\
\hline Auvergner & $6-7$ & $3-4$ & 6 & $5-6$ & 7 & $6-7$ & 0 & $2-3$ & 2 & 2 & 2 \\
\hline Azana & $6-7$ & $3-4$ & 6 & 5 & 7 & $5-6$ & 0 & $2-3$ & $2-3$ & 2 & 2 \\
\hline Babai & $6-7$ & 3 & $6-7$ & 5 & $7-8$ & 7 & 0 & 2 & $2-3$ & $1-2$ & 2 \\
\hline Badem-Erik & 7 & 4 & 6 & $5-6$ & 7 & 7 & 0 & 2 & 2 & 2 & $1-2$ \\
\hline Badoni & $6-7$ & 3 & $6-7$ & $4-5$ & $7-8$ & 7 & $0-1$ & $1-2$ & $2-3$ & 2 & 2 \\
\hline Bajrak & 7 & 3 & 7 & 5 & 8 & $7-8$ & 0 & 2 & $1-2$ & 2 & 2 \\
\hline Bal-jarümi & 7 & 3 & 7 & 5 & $8-9$ & $7-8$ & $0-1$ & $1-2$ & 2 & 2 & 1 \\
\hline Baneasa 4/71 & $6-7$ & $3-4$ & $6-7$ & $4-5$ & $7-8$ & $7-8$ & 0 & $1-2$ & 2 & 2 & 2 \\
\hline Baracca & $7-8$ & 3 & $6-7$ & 5 & 8 & 8 & 0 & 2 & $2-3$ & 2 & 2 \\
\hline Bayoto & 6 & $3-4$ & $6-7$ & $4-5$ & 7 & 7 & 0 & 2 & 2 & 2 & 2 \\
\hline Beangés & $6-7$ & 4 & 6 & $5-6$ & 7 & $6-7$ & 0 & $2-3$ & $2-3$ & 2 & $1-2$ \\
\hline Beauge & 6 & 4 & $6-7$ & $5-6$ & 7 & $6-7$ & 0 & 2 & 2 & $1-2$ & $1-2$ \\
\hline Bebeko & $7-8$ & 3 & 7 & 5 & $7-8$ & $7-8$ & 0 & $1-2$ & $2-3$ & 2 & 2 \\
\hline Bedri & 7 & $3-4$ & $6-7$ & 5 & 8 & 7 & 0 & 2 & $2-3$ & 2 & 2 \\
\hline Benmore & $6-7$ & 4 & $6-7$ & $5-6$ & 7 & 7 & 0 & 2 & 2 & 2 & 2 \\
\hline Bergarouge & $6-7$ & 4 & 6 & $5-6$ & $7-8$ & 7 & 0 & $1-2$ & $1-2$ & 2 & $1-2$ \\
\hline Bergeron & 6 & $3-4$ & 6 & $4-5$ & 8 & $6-7$ & 0 & $1-2$ & 1 & 2 & 3 \\
\hline Bhart & $6-7$ & 3 & 6 & 5 & $7-8$ & 7 & 0 & 2 & 2 & 1 & 1 \\
\hline Blanc rosé & $6-7$ & 4 & 6 & $4-5$ & $7-8$ & $6-7$ & 0 & 2 & 2 & 2 & 1 \\
\hline Blanchet & $6-7$ & $3-4$ & 6 & $4-5$ & $7-8$ & 7 & 0 & 2 & 2 & 2 & 2 \\
\hline Blenheim & 6 & 4 & 6 & 5 & 7 & $6-7$ & 0 & 2 & $2-3$ & 2 & 1 \\
\hline Blenril & 6 & 4 & $6-7$ & $5-6$ & 7 & $6-7$ & 0 & $1-2$ & $1-2$ & 2 & 2 \\
\hline Boccucida & $6-7$ & $3-4$ & 6 & $4-5$ & $7-8$ & 5 & 0 & 2 & 2 & 2 & 1 \\
\hline Boden Erik & 7 & 3 & 7 & $4-5$ & 7 & 7 & 0 & 2 & $2-3$ & $1-2$ & $1-2$ \\
\hline Bolsoj pozdnij & 6 & $3-4$ & $6-7$ & 4 & 7 & $6-7$ & 0 & 2 & $1-2$ & 2 & $1-2$ \\
\hline Bolsoj rannij & 6 & $3-4$ & $6-7$ & 4 & 7 & $6-7$ & 0 & $2-3$ & $2-3$ & 2 & $1-2$ \\
\hline Border Quenn & $6-7$ & 4 & 6 & $4-5$ & $7-8$ & $6-7$ & 0 & 2 & $2-3$ & 2 & 2 \\
\hline Borsi-féle kései rózsa & 6 & $3-4$ & $6-7$ & 4 & 8 & $6-7$ & 0 & $2-3$ & 1 & 2 & 2 \\
\hline Bökényi rózsa & 6 & $3-4$ & $6-7$ & 4 & 7 & 7 & 0 & 3 & 2 & 2 & 2 \\
\hline Braunauer & 6 & 4 & 6 & $4-5$ & 7 & $6-7$ & 0 & 2 & 2 & 2 & 2 \\
\hline Breda & $6-7$ & 4 & 6 & $5-6$ & 7 & 6 & 0 & $1-2$ & 2 & 2 & $1-2$ \\
\hline Brooks & 6 & 4 & 6 & $5-6$ & 7 & $6-7$ & 0 & 2 & $1-2$ & $1-2$ & 2 \\
\hline Budapest & 6 & $3-4$ & 6 & 4 & 8 & $6-7$ & 0 & 2 & $1-2$ & 2 & 3 \\
\hline
\end{tabular}




\begin{tabular}{|c|c|c|c|c|c|c|c|c|c|c|c|}
\hline Cultivar & $\mathrm{TB}$ & WB & $\mathrm{RB}$ & NB & LB & $\mathrm{KB}$ & SB & OP & FR & SS & DR \\
\hline Buhara & 7 & 3 & 7 & 5 & 8 & 8 & $0-1$ & $1-2$ & 1 & $1-2$ & 2 \\
\hline Bukurija & 7 & 3 & 7 & 5 & $8-9$ & $7-8$ & 0 & $3-4$ & 3 & 2 & $1-2$ \\
\hline Bulida & $6-7$ & $3-4$ & 6 & $4-5$ & 8 & 7 & 0 & $1-2$ & 3 & $1-2$ & $1-2$ \\
\hline Bungo (mume) & 7 & 4 & $5-6$ & 4 & 7 & 6 & 0 & 2 & 1 & $1-2$ & $1-2$ \\
\hline Bussières Triumph & 6 & 4 & 6 & $4-5$ & 7 & 6 & 0 & 2 & $2-3$ & 2 & 2 \\
\hline C. 326 & 6 & 4 & 6 & 4 & $7-8$ & $6-7$ & 0 & 2 & 2 & 2 & $1-2$ \\
\hline C. 333 & 6 & 4 & 6 & 4 & $7-8$ & $6-7$ & 0 & $2-3$ & 2 & 2 & 2 \\
\hline Cafona & $6-7$ & $3-4$ & 6 & $4-5$ & 8 & 5 & 0 & $1-2$ & 2 & $1-2$ & $1-2$ \\
\hline Caldesi 2 & 7 & 3 & 7 & $4-5$ & $7-8$ & 7 & 0 & $2-3$ & $2-3$ & 2 & $1-2$ \\
\hline Callatis & $6-7$ & 3 & $6-7$ & $4-5$ & $7-8$ & $6-7$ & 0 & 2 & 3 & 2 & 2 \\
\hline Canino & $6-7$ & $3-4$ & 6 & $4-5$ & 8 & 5 & 0 & 2 & 2 & 1 & $1-2$ \\
\hline Castelbrite & $6-7$ & 4 & $6-7$ & 5 & 9 & 7 & 0 & 2 & 2 & 2 & 2 \\
\hline Çataloglu & $7-8$ & 3 & 7 & 5 & 8 & 7 & 0 & $1-2$ & $2-3$ & $1-2$ & $1-2$ \\
\hline Ceglédi arany & $6-7$ & $3-4$ & $6-7$ & $4-5$ & 8 & $6-7$ & 0 & $1-2$ & 1 & $1-2$ & $1-2$ \\
\hline Ceglédi bíborkajszi C. 244 & 7 & $3-4$ & $6-7$ & $4-5$ & $7-8$ & 7 & 0 & $2-3$ & 3 & 1 & 1 \\
\hline Ceglédi bíborkajszi C. 307 & 7 & 4 & $6-7$ & 5 & $7-8$ & 7 & 0 & 2 & $2-3$ & 1 & 2 \\
\hline Ceglédi gömbölyü & $6-7$ & $3-4$ & 7 & $4-5$ & 8 & 7 & 0 & 2 & 2 & 3 & $1-2$ \\
\hline Ceglédi hajnalpír & $6-7$ & $3-4$ & 7 & $4-5$ & $7-8$ & 7 & 0 & 2 & 2 & 3 & 2 \\
\hline Ceglédi kedves & 7 & $3-4$ & 7 & $4-5$ & 8 & $6-7$ & 0 & 2 & 2 & 2 & 2 \\
\hline Ceglédi napsugár & 7 & $3-4$ & $6-7$ & $4-5$ & 8 & $6-7$ & 0 & $2-3$ & 2 & $1-2$ & $1-2$ \\
\hline Ceglédi óriás & $6-7$ & $3-4$ & $6-7$ & $4-5$ & $7-8$ & 7 & 0 & 3 & 2 & 2 & 2 \\
\hline Ceglédi Piroska & 7 & $3-4$ & 7 & $4-5$ & 8 & $6-7$ & 0 & $2-3$ & $2-3$ & 2 & 3 \\
\hline Ceglédi szilárd & 7 & $3-4$ & 7 & $4-5$ & 8 & $6-7$ & 0 & $1-2$ & $1-3$ & $1-2$ & $1-2$ \\
\hline Çigli & 7 & 3 & $6-7$ & 5 & 8 & $7-8$ & 0 & 2 & $2-3$ & 2 & 2 \\
\hline Comander & $6-7$ & $3-4$ & $6-7$ & $4-5$ & $7-8$ & $6-7$ & 0 & $2-3$ & 2 & $1-2$ & 2 \\
\hline Corred & $6-7$ & 3 & 6 & $5-6$ & 7 & 7 & 0 & 2 & 2 & 3 & 2 \\
\hline Cotoy & $6-7$ & $3-4$ & 6 & 5 & $7-8$ & 6 & 0 & 3 & 2 & 2 & 2 \\
\hline Cöluglu & $7-8$ & 3 & 7 & 5 & 9 & 7 & 0 & $1-2$ & $2-3$ & 2 & $1-2$ \\
\hline Currot & $6-7$ & $3-4$ & $6-7$ & $5-6$ & 7 & $6-7$ & 0 & 2 & 2 & 2 & 2 \\
\hline Csipogó barack (Korai piros) & 6 & $3-4$ & $6-7$ & 4 & 7 & 6 & 0 & 3 & $2-3$ & $1-2$ & $1-2$ \\
\hline Csongrádi Magyar kajszi & $6-7$ & 4 & $6-7$ & $4-5$ & $7-8$ & $6-7$ & 0 & 2 & 2 & $2-3$ & 2 \\
\hline Delgosha Tabrize & 7 & 3 & 7 & $4-5$ & $7-8$ & $6-7$ & 0 & 2 & 2 & $1-2$ & $1-2$ \\
\hline Delta & 7 & 4 & $6-7$ & 6 & 8 & $6-7$ & 0 & 2 & 2 & 2 & 1 \\
\hline Derbi-Royal & $6-7$ & 4 & 6 & 6 & 7 & 6 & 0 & 2 & 2 & $2-3$ & 2 \\
\hline Docteur Muscle & $6-7$ & $3-4$ & 6 & 4 & $7-8$ & $5-6$ & 0 & $1-2$ & 2 & 2 & $1-2$ \\
\hline Drjanovszka & $6-7$ & 4 & 6 & 4 & 8 & 6 & 0 & $2-3$ & 2 & $2-3$ & 1 \\
\hline Dunstan & $6-7$ & 3 & $6-7$ & $4-5$ & $7-8$ & 6 & 0 & $2-3$ & 2 & 2 & $1-2$ \\
\hline Dzsauravinszkij & 6 & 3 & $6-7$ & 5 & $7-8$ & 6 & 0 & $1-2$ & 2 & 2 & 2 \\
\hline Early Gold & 6 & 4 & $6-7$ & $5-6$ & 7 & $6-7$ & 0 & 2 & 2 & $1-2$ & 2 \\
\hline Early Orange & 6 & $3-4$ & 6 & $5-6$ & 7 & $6-7$ & 0 & $1-2$ & 2 & $1-2$ & $1-2$ \\
\hline Early Red & 6 & $3-4$ & 6 & $5-6$ & 7 & $6-7$ & 0 & $1-2$ & $2-3$ & 2 & 2 \\
\hline Early Royal & 6 & $3-4$ & $6-7$ & $5-6$ & 7 & $6-7$ & 0 & 2 & 2 & 2 & 2 \\
\hline Eatliril & $6-7$ & $3-4$ & $6-7$ & $5-6$ & 7 & $6-7$ & 0 & 2 & 3 & 2 & 2 \\
\hline Ekovickogo & 6 & 4 & 6 & 4 & 7 & 6 & 0 & 2 & $1-2$ & 2 & $1-2$ \\
\hline Ethembey & $7-8$ & 3 & 7 & 5 & $8-9$ & 7 & 0 & $1-2$ & $2-3$ & 2 & 2 \\
\hline Fantasme & $6-7$ & $3-4$ & 6 & 5 & 7 & 7 & 0 & 2 & 2 & 2 & 2 \\
\hline Faralia & 7 & 3 & 7 & 5 & $7-8$ & 7 & 0 & 2 & 2 & $1-2$ & $1-2$ \\
\hline
\end{tabular}




\begin{tabular}{|c|c|c|c|c|c|c|c|c|c|c|c|}
\hline Cultivar & $\mathrm{TB}$ & WB & $\mathrm{RB}$ & $\mathrm{NB}$ & LB & $\mathrm{KB}$ & SB & $\mathrm{OP}$ & FR & SS & DR \\
\hline Fekete kajszi & 7 & 3 & 7 & 4 & 9 & 7 & 0 & $2-3$ & $1-2$ & 2 & 2 \\
\hline Felfely & $7-8$ & 3 & $6-7$ & 5 & $7-8$ & 7 & 0 & 3 & 2 & 2 & 1 \\
\hline Fortuna & 7 & $3-4$ & $6-7$ & $4-5$ & $7-8$ & $6-7$ & 0 & 2 & 2 & $1-2$ & 2 \\
\hline Fracasso & $7-8$ & 3 & 7 & $4-5$ & $8-9$ & 7 & 0 & $2-3$ & $2-3$ & 2 & $1-2$ \\
\hline Francesco & 7 & 3 & $6-7$ & $4-5$ & 8 & 7 & 0 & 2 & $2-3$ & 2 & 2 \\
\hline Francia barack & $6-7$ & $3-4$ & 6 & $5-6$ & $7-8$ & $6-7$ & 0 & $1-2$ & 2 & 2 & $1-2$ \\
\hline Frühe Monplaisir & 6 & 4 & 6 & $5-6$ & $7-8$ & 6 & 0 & 2 & $1-2$ & 2 & 2 \\
\hline Gabriel & $6-7$ & 4 & $6-7$ & $4-5$ & 7 & 6 & 0 & 2 & 2 & $1-2$ & $1-2$ \\
\hline Gallatis & $6-7$ & $3-4$ & $6-7$ & $4-5$ & $7-8$ & $6-7$ & 0 & $1-2$ & 2 & 2 & 2 \\
\hline Galta Rocha & 7 & $3-4$ & 6 & $4-5$ & $7-8$ & $6-7$ & 0 & 2 & $2-3$ & 1 & 2 \\
\hline Ganacseni & $6-7$ & 3 & 6 & 5 & $7-8$ & $6-7$ & 0 & $2-3$ & 2 & 2 & 2 \\
\hline Gegdzsanabad & $6-7$ & 3 & 6 & 5 & 8 & 7 & 0 & 2 & $1-2$ & 2 & $1-2$ \\
\hline Gemszkirk & 6 & 4 & $5-6$ & 4 & 7 & 6 & 0 & 3 & 1 & 2 & 2 \\
\hline Geneva & $6-7$ & $3-4$ & $6-7$ & $5-6$ & 7 & 6 & 0 & 2 & 3 & 2 & 2 \\
\hline Ghorban & 7 & 3 & $6-7$ & 5 & $7-8$ & 7 & 0 & 2 & 2 & $1-2$ & $1-2$ \\
\hline Gimesta & $6-7$ & $3-4$ & 7 & $5-6$ & 7 & $6-7$ & 0 & 2 & 2 & 2 & 2 \\
\hline Gitano & 7 & 3 & 7 & 5 & $7-8$ & 7 & 0 & $1-2$ & 3 & 2 & $1-2$ \\
\hline Glattschalige Frühmarille & 6 & $3-4$ & $6-7$ & $5-6$ & 7 & 6 & 0 & $1-2$ & 1 & 1 & $1-2$ \\
\hline Goldcot & 6 & 4 & 6 & $5-6$ & 7 & $6-7$ & 0 & $1-2$ & $1-2$ & 2 & 2 \\
\hline Golden Nuggat & 6 & 4 & 6 & $5-6$ & 7 & $6-7$ & 0 & 2 & 2 & 2 & 1 \\
\hline Goldrich & 6 & 4 & 6 & $5-6$ & 7 & $6-7$ & 0 & 3 & 2 & $1-2$ & 1 \\
\hline Gönci barack 83 & 7 & $3-4$ & $6-7$ & $4-5$ & 7 & $6-7$ & 0 & 2 & 2 & $1-2$ & 2 \\
\hline Gönci Magyar kajszi & 7 & $3-4$ & $6-7$ & $4-5$ & $7-8$ & 7 & 0 & $1-2$ & $1-2$ & 2 & 2 \\
\hline Gönci sárga & $6-7$ & $3-4$ & $6-7$ & $4-5$ & $7-8$ & $6-7$ & 0 & 2 & $1-2$ & 2 & 2 \\
\hline Grosse gelbe & 6 & $3-4$ & 6 & $4-5$ & 7 & 6 & 0 & 2 & 1 & 2 & 2 \\
\hline Grose weisse Marille & 6 & $3-4$ & 6 & $4-5$ & 7 & 6 & 0 & $1-2$ & $1-2$ & 2 & 2 \\
\hline Grüne Spätmarille & 6 & 4 & 6 & $4-5$ & 7 & 6 & 0 & 2 & 1 & 2 & 1 \\
\hline Guljungi-Kurszadük & 7 & 3 & $6-7$ & 5 & 8 & 7 & $0-1$ & $1-2$ & $1-2$ & $1-2$ & 2 \\
\hline Gvadejszkij rannij & $5-6$ & $3-4$ & $5-6$ & $4-5$ & 7 & 6 & 0 & 2 & 2 & 2 & 2 \\
\hline Habrin & $5-6$ & 4 & $5-6$ & $4-5$ & 7 & 6 & 0 & 2 & 1 & $1-2$ & 1 \\
\hline Haci haliloglu & $7-8$ & 3 & 7 & 5 & 9 & $7-8$ & 0 & $1-2$ & 2 & 2 & 1 \\
\hline Hacikiz & $7-8$ & 3 & 7 & 5 & $8-9$ & $7-8$ & 0 & $1-2$ & $2-3$ & 2 & 2 \\
\hline Hamidi & 7 & 3 & $6-7$ & 5 & 8 & 7 & 0 & 2 & 2 & 1 & 2 \\
\hline $\begin{array}{l}\text { Hankovszky-féle kései } \\
\text { rózsa }\end{array}$ & 6 & 4 & 6 & 5 & 7 & 7 & 0 & 2 & $1-2$ & $2-3$ & 2 \\
\hline Harbinszkij Gluhova & 6 & $3-4$ & $5-6$ & $4-5$ & 7 & 6 & 0 & 2 & 1 & 2 & 1 \\
\hline Harcot & 7 & $3-4$ & $6-7$ & $4-5$ & $7-8$ & 7 & 0 & 3 & $2-3$ & $1-2$ & 2 \\
\hline Harglow & $6-7$ & 4 & 6 & $5-6$ & 7 & $6-7$ & 0 & $2-3$ & 2 & 2 & $1-2$ \\
\hline Hargrand & $6-7$ & 4 & 6 & $5-6$ & 7 & $6-7$ & 0 & $3-4$ & 2 & 2 & $1-2$ \\
\hline Harlayne & $6-7$ & 4 & 6 & $5-6$ & 7 & $6-7$ & 0 & 2 & 2 & 1 & 1 \\
\hline Harmat & 6 & $3-4$ & 6 & $4-5$ & 8 & $7-8$ & 0 & 3 & 3 & 2 & $1-2$ \\
\hline Harogem & $6-7$ & 4 & 6 & $5-6$ & 7 & $6-7$ & 0 & $2-3$ & 2 & 2 & 3 \\
\hline Hasambey & $7-8$ & 3 & $7-8$ & 5 & $8-9$ & $7-8$ & 0 & 2 & $2-3$ & $1-2$ & 2 \\
\hline Haszak & 7 & 3 & 7 & $5-6$ & 8 & $7-8$ & 0 & $2-3$ & $2-3$ & 2 & 2 \\
\hline Hatîf Colomer & $6-7$ & $3-4$ & 6 & 4 & 7 & $5-6$ & 0 & 2 & 2 & 2 & 1 \\
\hline Heimskircher & 6 & $3-4$ & 6 & $5-6$ & 7 & 6 & 0 & 2 & 2 & 2 & 2 \\
\hline Helena de Roussilion & $6-7$ & 4 & 6 & $5-6$ & 7 & $6-7$ & 0 & $1-2$ & 2 & 2 & $2-3$ \\
\hline
\end{tabular}




\begin{tabular}{|c|c|c|c|c|c|c|c|c|c|c|c|}
\hline Cultivar & $\mathrm{TB}$ & WB & $\mathrm{RB}$ & NB & LB & $\mathrm{KB}$ & SB & OP & FR & SS & DR \\
\hline Herson & 6 & 4 & 6 & 5 & 7 & $6-7$ & 0 & 2 & 2 & 2 & 2 \\
\hline Herszonszkij 26 & 6 & 4 & $5-6$ & $4-5$ & 7 & 6 & 0 & 2 & $2-3$ & 1 & 1 \\
\hline $\begin{array}{l}\text { Hetényi (Pukkadt) rózsa } \\
\text { C. } 777\end{array}$ & $6-7$ & $3-4$ & $6-7$ & 5 & 7 & 6 & 0 & 2 & $1-2$ & 3 & 2 \\
\hline H-I. 10/16 & $6-7$ & $3-4$ & $6-7$ & $4-5$ & $7-8$ & $6-7$ & 0 & 2 & 2 & 2 & $1-2$ \\
\hline H-I. 4/25 & $6-7$ & $3-4$ & $6-7$ & $4-5$ & 8 & $6-7$ & 0 & 2 & 2 & 2 & 2 \\
\hline H-II. 16/1 & $6-7$ & $3-4$ & 7 & $4-5$ & $7-8$ & $6-7$ & 0 & $1-2$ & $1-2$ & 2 & 2 \\
\hline H-II. 16/1 & $6-7$ & $3-4$ & $6-7$ & $4-5$ & $7-8$ & $6-7$ & 0 & 2 & 2 & $1-2$ & 1 \\
\hline H-II. 25/37 & $6-7$ & $3-4$ & $6-7$ & $4-5$ & $7-8$ & $6-7$ & 0 & 2 & 2 & 2 & $1-2$ \\
\hline H-II. 25/62 & $6-7$ & $3-4$ & $6-7$ & $4-5$ & 8 & $6-7$ & 0 & $1-2$ & $1-2$ & $1-2$ & 2 \\
\hline H-II. 45/26 & $6-7$ & $3-4$ & $6-7$ & $4-5$ & $7-8$ & $6-7$ & 0 & $1-2$ & 1 & 2 & 2 \\
\hline H-II. 45/26 & $6-7$ & $3-4$ & $6-7$ & $4-5$ & 8 & $6-7$ & 0 & 1 & 2 & 2 & $1-2$ \\
\hline H-II. 45/45 & $6-7$ & $3-4$ & $6-7$ & $4-5$ & $7-8$ & $6-7$ & 0 & $2-3$ & 2 & 2 & 2 \\
\hline Hollandi muskotály & 6 & 4 & 6 & $4-5$ & 7 & 6 & 0 & 2 & 2 & 2 & 1 \\
\hline Holub cukorkajszi & 6 & $3-4$ & 6 & $5-6$ & 7 & 6 & 0 & 2 & 2 & 2 & 3 \\
\hline Honigmarille & $6-7$ & $3-4$ & $6-7$ & $5-6$ & 7 & 6 & 0 & $2-3$ & 2 & 2 & 2 \\
\hline Hoszrovsai & 7 & 3 & $6-7$ & 5 & 7 & 6 & 0 & $1-2$ & $1-2$ & 2 & 2 \\
\hline Hulan & $6-7$ & 3 & 6 & $4-5$ & 7 & $6-7$ & 0 & 2 & 1 & $1-2$ & $1-2$ \\
\hline Hunter & 6 & 4 & 6 & 6 & 7 & 6 & 0 & $2-3$ & 2 & 2 & 2 \\
\hline Hurmai & 6 & 3 & 6 & 5 & $7-8$ & 7 & $0-1$ & 2 & 1 & $1-2$ & $1-2$ \\
\hline Hurmai citroszovüj & 6 & $3-4$ & 6 & $5-6$ & $7-8$ & 7 & 0 & 2 & 1 & $1-2$ & $1-2$ \\
\hline Imperial & $6-7$ & 4 & 6 & $5-6$ & 7 & 6 & 0 & $2-3$ & $1-2$ & 2 & $1-2$ \\
\hline Imrahor & $6-7$ & 3 & $6-7$ & 5 & 8 & $6-7$ & 0 & 2 & 1 & $1-2$ & $1-2$ \\
\hline Iri-Bitirgen & 7 & 3 & 7 & 5 & 8 & 7 & $0-1$ & $1-2$ & 2 & 2 & 2 \\
\hline Iszfarak & 6 & 4 & $6-7$ & 5 & $8-9$ & 8 & 0 & 2 & 1 & $1-2$ & $1-2$ \\
\hline Jerevani & $6-7$ & 5 & 7 & $5-6$ & $8-9$ & $7-8$ & 0 & $3-4$ & 1 & $1-2$ & $1-2$ \\
\hline Ji-pu & $6-7$ & 4 & 7 & 5 & 8 & $7-8$ & 0 & 2 & 2 & 2 & 2 \\
\hline Jitka & 6 & 4 & $6-7$ & $4-5$ & 7 & $6-7$ & 0 & 2 & 2 & 1 & 1 \\
\hline Június szépe & 6 & $3-4$ & $5-6$ & 4 & 7 & $6-7$ & 0 & $2-3$ & $2-3$ & 2 & 2 \\
\hline Junszkij & $5-6$ & 4 & $5-6$ & $4-5$ & 7 & 6 & 0 & $1-2$ & 2 & $1-2$ & 2 \\
\hline $\mathrm{K}-1 / 2$ & $6-7$ & $3-4$ & $6-7$ & 4 & $7-8$ & $6-7$ & 0 & 2 & 2 & $1-2$ & 2 \\
\hline K-3/101 & $6-7$ & $3-4$ & $6-7$ & 4 & $7-8$ & $6-7$ & 0 & 2 & 2 & 2 & $1-2$ \\
\hline K III. 5/12 & $6-7$ & $3-4$ & 6 & 4 & $7-8$ & $6-7$ & 0 & $1-2$ & $1-2$ & 2 & 2 \\
\hline Kabaaşi & $7-8$ & 3 & 7 & $5-6$ & $8-9$ & $7-9$ & $0-1$ & $2-3$ & 2 & 2 & 2 \\
\hline Kadu-hurmaj & 7 & 3 & 7 & 5 & 8 & 7 & 0 & $1-2$ & 1 & 1 & $1-2$ \\
\hline Kaischa (igazi Kajszi!) & $6-7$ & $3-4$ & 6 & 5 & 7 & 7 & 0 & 2 & $1-2$ & $1-2$ & $1-2$ \\
\hline Kancler & $6-7$ & $3-4$ & 7 & $5-6$ & 7 & 7 & 0 & 2 & $1-2$ & $1-2$ & 2 \\
\hline Kandak & $7-8$ & 3 & 7 & 5 & $8-9$ & 7 & 0 & $1-2$ & 1 & 2 & 2 \\
\hline Karacabey & $7-8$ & 3 & $7-8$ & 5 & 9 & $7-8$ & 0 & 2 & $2-3$ & $1-2$ & $1-2$ \\
\hline Kara-Olúhrod & 7 & 3 & 7 & $4-5$ & $7-8$ & $7-8$ & 0 & 2 & 1 & 1 & 1 \\
\hline Kécskei korai C. 242 & 6 & $3-4$ & $6-7$ & 4 & 7 & $6-7$ & 0 & 2 & 2 & 2 & 2 \\
\hline Kécskei rózsa C. 671 & 6 & $3-4$ & $6-7$ & 4 & 7 & $6-7$ & 0 & 2 & 2 & 3 & $1-2$ \\
\hline Kecskeméti korai & 6 & 4 & 6 & 4 & 7 & $6-7$ & 0 & $2-3$ & 2 & $1-2$ & 2 \\
\hline Kecskeméti rózsa C. 778 & 6 & $3-4$ & $6-7$ & 4 & 7 & $6-7$ & 0 & 2 & $1-2$ & 2 & 2 \\
\hline Kecs-psar & 7 & 3 & $7-8$ & 5 & 9 & 8 & 0 & 1 & 1 & 1 & 2 \\
\hline Kioto & 7 & 3 & $6-7$ & 5 & $7-8$ & $7-8$ & 0 & 1 & 2 & $1-2$ & $1-2$ \\
\hline Kizil-Olúhrod & 7 & 3 & 7 & 5 & 8 & $7-8$ & $0-1$ & 2 & 1 & 1 & 1 \\
\hline
\end{tabular}




\begin{tabular}{|c|c|c|c|c|c|c|c|c|c|c|c|}
\hline Cultivar & TB & WB & $\mathrm{RB}$ & NB & LB & $\mathrm{KB}$ & SB & $\mathrm{OP}$ & FR & SS & DR \\
\hline Kjar-Gjari & $7-8$ & 3 & 7 & 5 & 8 & 7 & $0-1$ & 2 & $1-2$ & 1 & 1 \\
\hline Klabi & 7 & 3 & 7 & 5 & 8 & 7 & 0 & $1-2$ & $2-3$ & 2 & 2 \\
\hline Kleine weisse Marille & $6-7$ & 4 & 6 & $4-5$ & $7-8$ & 6 & 0 & $2-3$ & 2 & $1-2$ & $1-2$ \\
\hline Klosterneuburger & 6 & 4 & 6 & $4-5$ & $7-8$ & 6 & 0 & 2 & 1 & $1-2$ & 2 \\
\hline Konobas & 7 & 3 & $6-7$ & 5 & 7 & $6-7$ & 0 & 2 & $1-2$ & 2 & 2 \\
\hline Korai piros (Csipogó barack) & 6 & $3-4$ & $6-7$ & 4 & $8-9$ & $6-7$ & 0 & 3 & 2 & $1-2$ & 2 \\
\hline Korai zamatos & $6-7$ & 4 & $6-7$ & $4-5$ & 8 & $7-8$ & 0 & 3 & 2 & 2 & 3 \\
\hline Korolevszkij & 6 & 4 & $5-6$ & $4-5$ & 7 & 6 & 0 & $2-3$ & 2 & 2 & 2 \\
\hline Koshu Saisho & 7 & 4 & $6-7$ & 6 & 8 & 7 & 0 & 2 & 2 & $1-2$ & $1-2$ \\
\hline Königsmarille & $6-6$ & $3-4$ & 6 & $5-6$ & 7 & 6 & 0 & 2 & 2 & 2 & 1 \\
\hline Krasznoscsokij (Pirospofás) & $6-7$ & 4 & $6-7$ & $4-5$ & 7 & $6-7$ & 0 & $2-3$ & $2-3$ & 1 & 1 \\
\hline Krasznoscsokij Nikitszkij & $6-7$ & 4 & $6-7$ & $4-5$ & 7 & $6-7$ & 0 & 2 & $2-3$ & 1 & 2 \\
\hline Krasznoscsokij pozdnij & $6-7$ & 4 & $6-7$ & $4-5$ & 7 & 7 & 0 & $2-3$ & 2 & $1-2$ & 2 \\
\hline Krasznüj partizan & 6 & $3-4$ & $6-7$ & $4-5$ & 7 & 6 & 0 & 2 & $1-2$ & 2 & $1-2$ \\
\hline Kremser & 6 & 4 & 6 & $5-6$ & 7 & 6 & 0 & $2-3$ & $1-2$ & 2 & 2 \\
\hline Krimszkij amur & 7 & $4-5$ & 7 & 5 & $7-8$ & 7 & 0 & 2 & 2 & $1-2$ & $1-2$ \\
\hline Krupna ranka & $6-7$ & 4 & $6-7$ & $4-5$ & $7-8$ & $6-7$ & 0 & $1-2$ & $1-2$ & $1-2$ & $1-2$ \\
\hline Krupnüj pozdnij & $6-7$ & 4 & $6-7$ & $4-5$ & $7-8$ & $6-7$ & 0 & 2 & 2 & 2 & 2 \\
\hline Krupnüj zsoltij & $6-7$ & 4 & $6-7$ & $4-5$ & $7-8$ & $6-7$ & 0 & 2 & 3 & 2 & 2 \\
\hline Kur Sadik & $7-8$ & $3-4$ & 7 & $5-6$ & $8-9$ & $7-8$ & $0-1$ & $1-2$ & $1-2$ & 2 & 2 \\
\hline Kuresia & 6 & 4 & 7 & 4 & 7 & $6-7$ & 0 & 2 & $1-2$ & $1-2$ & 1 \\
\hline Kurszadük & 7 & 4 & $6-7$ & 5 & $8-9$ & $7-8$ & 0 & 2 & $1-2$ & 2 & 1 \\
\hline Kuru Kabuk & 7 & $3-4$ & 7 & $4-5$ & 8 & $7-8$ & 0 & $1-2$ & $2-3$ & 2 & 2 \\
\hline Lambertin No. 1 & $6-7$ & 4 & 7 & $5-6$ & 7 & $6-7$ & 0 & 2 & 2 & 2 & 2 \\
\hline Larclyd & 6 & 4 & $5-6$ & $5-6$ & 7 & $6-7$ & 0 & 2 & 2 & 2 & 2 \\
\hline Leala & $6-7$ & 4 & 6 & $4-5$ & 7 & $6-7$ & 0 & 2 & $1-2$ & 2 & 2 \\
\hline Lenova & $6-7$ & 4 & 6 & $4-5$ & 7 & $6-7$ & 0 & 2 & 2 & $1-2$ & $1-2$ \\
\hline Lerosa & $6-7$ & 4 & 6 & $4-5$ & 7 & $6-7$ & 0 & 2 & 2 & 2 & 2 \\
\hline Leskova & $6-7$ & 4 & 6 & $4-5$ & 7 & $6-7$ & 0 & $2-3$ & 2 & $1-2$ & 2 \\
\hline Ligeti óriás & 7 & $3-4$ & $6-7$ & 4 & $7-8$ & 7 & 0 & $2-3$ & $1-2$ & 2 & $1-2$ \\
\hline Li-guang & $6-7$ & 4 & 7 & 6 & 8 & 7 & 0 & 2 & 2 & 1 & 1 \\
\hline Litoral & $6-7$ & $3-4$ & $6-7$ & $4-5$ & $7-8$ & 7 & 0 & 2 & 2 & 2 & 2 \\
\hline Little Sun & 6 & 4 & 6 & $5-6$ & 7 & 6 & 0 & 2 & $1-2$ & 2 & $1-2$ \\
\hline Löschnig Marille & 6 & 4 & 6 & 5 & 7 & 5 & 0 & 2 & $1-2$ & 2 & 2 \\
\hline Lucssij Micsurinszkij & 6 & 4 & $5-6$ & $4-5$ & 7 & 6 & 0 & 2 & 1 & 1 & 2 \\
\hline Luizet & $6-7$ & $3-4$ & $6-7$ & $4-5$ & $7-8$ & $5-6$ & 0 & 2 & 1 & 2 & 2 \\
\hline Luna & $6-7$ & $3-4$ & 6 & 6 & $7-8$ & 6 & 0 & $2-3$ & 2 & 2 & 2 \\
\hline Magiccot & 7 & 4 & 6 & 6 & $7-8$ & 6 & 0 & $1-2$ & $1-2$ & 2 & 2 \\
\hline Magyar kajszi C, 602 & $6-7$ & $3-4$ & $6-7$ & $4-5$ & $7-8$ & 7 & 0 & 1 & 2 & 2 & 2 \\
\hline Magyar kajszi C. 1685 & $6-7$ & $3-4$ & $6-7$ & $4-5$ & $7-8$ & 7 & 0 & $1-2$ & $1-2$ & 2 & 2 \\
\hline Magyar kajszi C. 235 & $6-7$ & $3-4$ & $6-7$ & $4-5$ & 8 & 7 & 0 & $1-2$ & 2 & 2 & $1-2$ \\
\hline Magyar kajszi C. 256 & $6-7$ & $3-4$ & $6-7$ & $4-5$ & $7-8$ & 7 & 0 & $1-2$ & 2 & 2 & $1-2$ \\
\hline Magyar kajszi C. 302 & $6-7$ & $3-4$ & $6-7$ & $4-5$ & 8 & 7 & 0 & 2 & 2 & $1-2$ & 2 \\
\hline Magyar kajszi C. 501 & $6-7$ & $3-4$ & $6-7$ & $4-5$ & $7-8$ & 7 & 0 & 2 & $1-2$ & 2 & 2 \\
\hline Magyar kajszi C. 617 & $6-7$ & $3-4$ & $6-7$ & $4-5$ & $7-8$ & 7 & 0 & $1-2$ & 2 & $1-2$ & $1-2$ \\
\hline Magyar kajszi C. 660 & $6-7$ & $3-4$ & $6-7$ & $4-5$ & $7-8$ & 7 & 0 & 2 & 2 & 2 & $1-2$ \\
\hline Magyar legjobb & 6 & 4 & $6-7$ & $4-5$ & 7 & $6-7$ & 0 & $1-2$ & $1-2$ & 2 & $1-2$ \\
\hline
\end{tabular}




\begin{tabular}{|c|c|c|c|c|c|c|c|c|c|c|c|}
\hline Cultivar & TB & WB & $\mathrm{RB}$ & NB & LB & $\mathrm{KB}$ & SB & OP & FR & SS & DR \\
\hline Mahmudn Erigli & $7-8$ & 4 & 7 & 5 & 8 & 7 & 0 & 2 & 2 & 2 & $1-2$ \\
\hline Mahtobi-dzsaupazak-kandü & 7 & 4 & 7 & 5 & $8-9$ & 7 & 0 & $2-3$ & 2 & 1 & 2 \\
\hline Mai-huang-hszing & $6-7$ & 4 & $6-7$ & 5 & $7-8$ & 7 & 0 & 2 & 2 & 2 & 2 \\
\hline Majombarack & 6 & 4 & 6 & 4 & 7 & $7-8$ & 0 & 1 & $1-2$ & $1-2$ & $1-2$ \\
\hline Malatya & $7-8$ & $4-5$ & 7 & 5 & 9 & $6-7$ & 0 & $1-2$ & 2 & 2 & 2 \\
\hline Malayerri & 7 & 4 & 7 & $5-6$ & $7-8$ & $6-7$ & 0 & $1-2$ & 1 & $1-2$ & 2 \\
\hline Malice & 7 & $3-4$ & $6-7$ & $5-6$ & 8 & $6-7$ & 0 & $2-3$ & $2-3$ & $2-3$ & 2 \\
\hline Mamaia & $6-7$ & $3-4$ & $6-7$ & $4-5$ & $7-8$ & $6-7$ & 0 & 2 & 2 & 2 & 2 \\
\hline Manchu & $7-8$ & 3 & $6-7$ & $4-5$ & 8 & 6 & 0 & $1-2$ & 1 & 1 & 1 \\
\hline $\begin{array}{l}\text { Mandulakajszi (Erős-féle } \\
\text { kései) }\end{array}$ & 6 & $3-4$ & $6-7$ & $4-5$ & $7-8$ & $6-7$ & 0 & 3 & 2 & 2 & 2 \\
\hline Mandulakajszi C. 712 & 6 & $3-4$ & 6 & $4-5$ & 8 & $5-6$ & 0 & $2-3$ & 2 & 2 & $1-2$ \\
\hline Mandzsu (sibirica) & $5-6$ & $3-4$ & 5 & 4 & 7 & $5-6$ & 0 & 1 & $1-2$ & 2 & 1 \\
\hline Mauricio & $7-8$ & $3-4$ & $6-7$ & 5 & 8 & 7 & 0 & 2 & 3 & 2 & $2-3$ \\
\hline Mech-mech & $7-8$ & $4-5$ & $7-8$ & 5 & 9 & $7-8$ & $0-1$ & $1-2$ & 3 & 2 & 2 \\
\hline Micsurinszkij lucssij & $5-6$ & 5 & $5-5$ & $4-5$ & 7 & 6 & 0 & 2 & 1 & $1-2$ & 1 \\
\hline Mirmai & $6-7$ & 5 & 6 & $4-5$ & $7-8$ & 7 & 0 & 2 & 1 & $1-2$ & $1-2$ \\
\hline Mirszandzsali & 6 & 4 & $6-7$ & 5 & 8 & $6-7$ & 0 & 1 & $1-2$ & $1-2$ & 1 \\
\hline Mk 132-5 & $6-7$ & $3-4$ & $6-7$ & $4-5$ & $7-8$ & 7 & 0 & 2 & 2 & $1-2$ & 2 \\
\hline Mk. 150 & $6-7$ & $3-4$ & $6-7$ & $4-5$ & $7-8$ & 7 & 0 & $1-2$ & 2 & 2 & 2 \\
\hline Monaco Bello & 7 & 4 & $6-7$ & $5-6$ & 8 & 7 & 0 & 2 & 3 & 2 & 2 \\
\hline Mongol & $5-6$ & 3 & $5-6$ & $4-5$ & 8 & $5-6$ & 0 & $2-3$ & 1 & 2 & $1-2$ \\
\hline Moniqui & $6-7$ & 4 & $6-7$ & 5 & $8-9$ & 5 & 0 & $1-2$ & $2-3$ & 2 & 2 \\
\hline Moongold & 6 & $3-4$ & 6 & 5 & 8 & 6 & 0 & 2 & 1 & 2 & 2 \\
\hline Montgamet & 6 & $3-4$ & $5-6$ & $5-6$ & $8-9$ & 6 & 0 & 2 & 2 & $1-2$ & $1-2$ \\
\hline Moorpark & $6-7$ & $3-4$ & 6 & 4 & 7 & $5-6$ & 0 & 3 & $2-3$ & 2 & $2-3$ \\
\hline Morden & 6 & 4 & 6 & $4-5$ & 7 & 6 & 0 & $1-2$ & 1 & $1-2$ & 2 \\
\hline Mund & 6 & 4 & 6 & $5-6$ & $7-8$ & 6 & 0 & 2 & 2 & 2 & 2 \\
\hline Musa & 7 & $4-5$ & 6 & 5 & $7-8$ & $6-7$ & 0 & $2-3$ & $2-3$ & 2 & 2 \\
\hline Musa-Amar & 7 & 4 & 7 & 5 & $8-9$ & $7-8$ & 0 & $1-2$ & $1-2$ & 1 & 1 \\
\hline Muskotály barack & $6-7$ & 4 & 6 & $4-5$ & 8 & 7 & 0 & 2 & 2 & $2-3$ & $2-3$ \\
\hline Mus-Mus & $7-8$ & 4 & 7 & 5 & 9 & $7-8$ & $0-1$ & 2 & $2-3$ & $1-2$ & 2 \\
\hline Myrobalán kajszi C. 308 & 7 & 4 & 6 & $5-6$ & 7 & 7 & 0 & 3 & 1 & 2 & 2 \\
\hline Nagyenyedi kajszi & $6-7$ & $3-4$ & 6 & 4 & 7 & 7 & 0 & $1-2$ & 2 & 2 & 2 \\
\hline Nagykőrösi óriás & $6-7$ & $3-4$ & $6-7$ & $4-5$ & $7-8$ & $6-7$ & 0 & 3 & 2 & 2 & $1-2$ \\
\hline Nagyszombati kajszi & 6 & $3-4$ & 6 & 4 & $6-7$ & 7 & 0 & 2 & 2 & 2 & $2-3$ \\
\hline Nahicsevanszkij krasznüj & 6 & 4 & 7 & $5-6$ & 8 & 7 & 0 & 2 & 2 & 2 & 2 \\
\hline Nahudka & $6-7$ & $3-4$ & 6 & 5 & 8 & 7 & 0 & $2-3$ & 2 & $1-2$ & $1-2$ \\
\hline Nancy (Luxemburgi) & $6-7$ & $3-4$ & 6 & $4-5$ & 8 & $5-6$ & 0 & $1-2$ & 2 & 2 & 3 \\
\hline Naramata & 7 & 4 & $6-7$ & 5 & $7-8$ & 7 & 0 & 2 & 2 & 2 & 1 \\
\hline Nashi & 7 & 4 & $6-7$ & 5 & $7-8$ & 7 & 0 & $1-2$ & $2-3$ & 1 & $1-2$ \\
\hline Nektar & $6-7$ & 3 & 6 & $5-6$ & 7 & 7 & 0 & 2 & 2 & $2-3$ & 2 \\
\hline New Jersey A. 1 & 6 & $3-4$ & 6 & $5-6$ & $7-8$ & 6 & 0 & 2 & $1-2$ & 2 & 2 \\
\hline Newcastle & 6 & 3 & 6 & $5-6$ & 7 & $6-7$ & 0 & $1-2$ & 2 & $1-2$ & $1-2$ \\
\hline Nikitszkij & $6-7$ & $3-4$ & $6-7$ & $4-5$ & 8 & $6-7$ & 0 & 2 & 2 & $1-2$ & 2 \\
\hline Nimfa & 7 & 4 & 6 & $5-6$ & $7-8$ & $6-7$ & 0 & $1-2$ & 2 & $2-3$ & 1 \\
\hline Novraszt belüj & $5-6$ & 4 & 6 & $4-5$ & 7 & 6 & 0 & 2 & 2 & 2 & 2 \\
\hline
\end{tabular}




\begin{tabular}{|c|c|c|c|c|c|c|c|c|c|c|c|}
\hline Cultivar & TB & WB & $\mathrm{RB}$ & NB & LB & KB & SB & $\mathrm{OP}$ & FR & SS & DR \\
\hline Novraszt krasznüj & $5-6$ & $3-4$ & 6 & $4-5$ & 7 & 6 & 0 & 2 & $1-2$ & $1-2$ & 2 \\
\hline Nugget & 6 & $3-4$ & 6 & $5-6$ & 7 & 6 & 0 & $1-2$ & 2 & 2 & 1 \\
\hline Nyujtó Ferenc emléke & $6-7$ & $3-4$ & $6-7$ & $4-5$ & $7-8$ & $6-7$ & 0 & $1-2$ & $1-2$ & $1-2$ & $1-2$ \\
\hline Old Moorpark & 6 & $3-4$ & 6 & $5-6$ & 7 & 6 & 0 & 2 & 2 & 2 & 2 \\
\hline Olimp & $6-7$ & $3-4$ & $6-7$ & 5 & $7-8$ & 7 & 0 & $2-3$ & 2 & 2 & $1-2$ \\
\hline Onossay-féle kajszi & $6-7$ & $3-4$ & $6-7$ & $4-5$ & $7-8$ & $6-7$ & 0 & 2 & 2 & 2 & 1 \\
\hline Orange Marille & 6 & $3-4$ & 6 & $5-6$ & $7-8$ & $6-7$ & 0 & 2 & 1 & 2 & 2 \\
\hline Orange Red & 6 & $3-4$ & 6 & $5-6$ & $7-8$ & $6-7$ & 0 & 3 & 2 & 2 & 3 \\
\hline Oranzsevoj krasznüj & 6 & 3 & 6 & $4-5$ & 7 & 6 & 0 & 2 & 2 & 1 & $1-2$ \\
\hline Oranzsevoj pozdnij & 6 & 3 & 6 & $4-5$ & 7 & 6 & 0 & 2 & 2 & 1 & 1 \\
\hline Oranzsevoj sztojkij & 6 & $3-4$ & 6 & $4-5$ & 7 & 6 & 0 & $1-2$ & 2 & 1 & 1 \\
\hline Ordubadi & $7-8$ & 4 & $6-7$ & 5 & 8 & 7 & 0 & 2 & 3 & 2 & $1-2$ \\
\hline Overnszkij szkoroszpelüj & 6 & 4 & $5-6$ & $4-5$ & 7 & 6 & 0 & $1-2$ & $1-2$ & $1-2$ & $1-2$ \\
\hline Paksi Magyar kajszi & $6-7$ & $3-4$ & $6-7$ & $4-5$ & $7-8$ & 7 & 0 & 2 & $1-2$ & 2 & 2 \\
\hline Palau & $6-7$ & $3-4$ & 6 & 5 & 7 & $5-6$ & 0 & 2 & $1-2$ & 2 & $1-2$ \\
\hline Pannónia & 6 & $3-4$ & 6 & $4-5$ & 8 & $6-7$ & 0 & $1-2$ & 2 & $2-3$ & 2 \\
\hline Pannwach & $6-7$ & $3-4$ & $5-6$ & $5-6$ & 7 & $6-7$ & 0 & 2 & 2 & 2 & 2 \\
\hline Paviot & $6-7$ & 4 & 6 & $4-5$ & 8 & $6-7$ & 0 & 2 & $1-2$ & 2 & $1-2$ \\
\hline Pécsi óriás & $6-7$ & $3-4$ & 6 & $4-5$ & $7-8$ & 7 & 0 & $2-3$ & 2 & 2 & 2 \\
\hline Peeka & 7 & $3-4$ & $6-7$ & $5-6$ & $7-8$ & $6-7$ & 0 & $2-3$ & $2-3$ & $1-2$ & 2 \\
\hline Pellecchiella & 7 & 4 & 7 & 5 & 8 & 7 & 0 & 2 & 3 & 2 & 2 \\
\hline Pepito de Rubio & $7-8$ & 4 & 7 & 5 & $8-9$ & 7 & 0 & 2 & $2-3$ & 2 & $1-2$ \\
\hline Perfection & $6-7$ & $3-4$ & 6 & $4-5$ & $7-8$ & 6 & 0 & 3 & $1-2$ & 2 & $1-2$ \\
\hline Perla & 7 & $3-4$ & $7-8$ & 5 & 8 & 7 & 0 & 2 & $2-3$ & $1-2$ & $1-2$ \\
\hline Piros kajszi & 6 & $3-4$ & 7 & $4-5$ & $7-8$ & 7 & 0 & $2-3$ & 2 & 2 & 2 \\
\hline Pirospofás & $6-7$ & $3-4$ & 7 & $4-5$ & $7-8$ & 7 & 0 & 2 & 2 & 1 & 2 \\
\hline Podarok & 6 & $3-4$ & 6 & $4-5$ & $7-8$ & 7 & 0 & $1-2$ & 2 & 2 & 2 \\
\hline Polonais & 6 & $3-4$ & 6 & $4-5$ & 8 & 6 & 0 & $2-3$ & $2-3$ & 2 & $1-2$ \\
\hline Polummella & $7-8$ & 4 & 7 & $4-5$ & 8 & 7 & 0 & $2-3$ & 3 & 2 & $1-2$ \\
\hline Portici & $7-8$ & 4 & $5-7$ & 5 & 8 & 8 & 0 & $2-3$ & $2-3$ & 3 & $2-3$ \\
\hline Portugal & 7 & 4 & $7-8$ & 5 & $8-9$ & $8-9$ & 0 & 2 & 3 & 2 & 2 \\
\hline Précoce de de Boulbon & $6-7$ & $3-4$ & $6-7$ & $5-6$ & $7-8$ & $6-7$ & 0 & $1-2$ & $2-3$ & 2 & 2 \\
\hline Précoce de Monplaisir & 6 & 4 & $6-7$ & 4 & $7-8$ & $5-6$ & 0 & 2 & 2 & 2 & 2 \\
\hline Priboto (Zebra) & $6-7$ & $3-4$ & $6-7$ & $4-5$ & $7-8$ & 7 & 0 & 2 & 2 & 1 & 2 \\
\hline Priszudebnij rannij & $6-7$ & $3-4$ & $6-7$ & 4 & 7 & 7 & $0-1$ & 2 & $1-2$ & 1 & 1 \\
\hline Progressz & 6 & 3 & $6-7$ & $4-5$ & 7 & 7 & 0 & $2-3$ & 1 & $1-2$ & $1-2$ \\
\hline Provance-i & 7 & $4-5$ & $7-6$ & 5 & 8 & 7 & 0 & 2 & 3 & 2 & $2-3$ \\
\hline Purpurovüj & $7-8$ & $4-5$ & 7 & 5 & 7 & $7-8$ & 0 & 2 & $1-2$ & 2 & 2 \\
\hline Rakovszky kajszi & $6-7$ & $3-4$ & 6 & 4 & $8-9$ & $6-7$ & 0 & $1-2$ & 2 & 3 & 3 \\
\hline Reale d'Imola & $6-7$ & 4 & 7 & $4-5$ & $8-9$ & $5-6$ & 0 & 2 & $1-2$ & 2 & $1-2$ \\
\hline Red Reinbow & $6-7$ & $3-4$ & 6 & 6 & $7-8$ & 6 & 0 & 2 & $1-2$ & 2 & 2 \\
\hline Redsweet & $6-7$ & $3-4$ & $6-7$ & 6 & $7-8$ & $5-6$ & 0 & 2 & $1-2$ & 2 & 2 \\
\hline Reece & $6-7$ & 3 & 6 & $5-6$ & 7 & $5-6$ & 0 & $2-3$ & $2-3$ & 2 & $1-2$ \\
\hline Reeves & 6 & $3-4$ & 6 & $5-6$ & 7 & $5-6$ & 0 & 2 & 2 & $1-2$ & 2 \\
\hline Reliable & 6 & $3-4$ & 6 & $5-6$ & 7 & 6 & 0 & $1-2$ & 2 & 2 & 2 \\
\hline Riland & 6 & $3-4$ & 6 & $4-5$ & 7 & 6 & 0 & $2-3$ & 2 & 2 & 2 \\
\hline Robada & $6-7$ & 4 & 6 & 5 & $7-8$ & 6 & 0 & 2 & $2-3$ & 2 & $1-2$ \\
\hline
\end{tabular}




\begin{tabular}{|c|c|c|c|c|c|c|c|c|c|c|c|}
\hline Cultivar & $\mathrm{TB}$ & WB & $\mathrm{RB}$ & NB & LB & $\mathrm{KB}$ & SB & OP & FR & SS & DR \\
\hline Római barack & 7 & 3 & $7-8$ & 5 & 8 & 8 & 0 & $2-3$ & 2 & 2 & 2 \\
\hline Rose Fournes & 7 & $3-4$ & $6-7$ & $5-6$ & $7-8$ & $6-7$ & 0 & 2 & $1-2$ & $1-2$ & 2 \\
\hline Rouge de Rivesaltes & 6 & $3-4$ & 6 & $4-5$ & 7 & $6-7$ & 0 & $2-3$ & 2 & 2 & 1 \\
\hline Rouge de Roussillon & 6 & $3-4$ & $6-7$ & $4-5$ & 7 & $6-7$ & 0 & $1-2$ & 2 & 2 & $1-2$ \\
\hline Rouge de Sernhac & 6 & $3-4$ & $6-7$ & 4 & 7 & $6-7$ & 0 & 2 & $2-3$ & 3 & 3 \\
\hline Roxana & $6-7$ & $3-4$ & $6-7$ & $4-5$ & $7-8$ & $7-8$ & 0 & $2-3$ & 3 & 2 & 3 \\
\hline Roxburgh Red & 6 & 3 & $6-7$ & 6 & 7 & $6-7$ & 0 & 2 & 2 & 2 & 2 \\
\hline Royal (Blenheim) & $6-7$ & $3-4$ & $6-7$ & $4-5$ & $7-8$ & $7-8$ & 0 & $1-2$ & 2 & 2 & 3 \\
\hline Rózsabarack C.1478 & 6 & $3-4$ & $6-7$ & 4 & $7-8$ & $7-8$ & 0 & 2 & $2-3$ & 2 & $1-2$ \\
\hline Rózsakajszi C.1406 & $6-7$ & $3-4$ & $6-7$ & 4 & $7-8$ & $7-8$ & 0 & 2 & $1-2$ & 2 & 2 \\
\hline Ruhi Dzsuvani & 6 & $4-5$ & 7 & 5 & 8 & 8 & 0 & $2-3$ & 1 & 1 & $1-2$ \\
\hline Rumjanij & $6-7$ & $3-4$ & 6 & $4-5$ & $7-8$ & 7 & 0 & 2 & 3 & 2 & $1-2$ \\
\hline Sakit 2 & $7-8$ & $3-4$ & 6 & 4 & $7-8$ & 7 & 0 & 2 & 2 & 2 & 2 \\
\hline Salah & $6-7$ & $4-5$ & 7 & $5-6$ & $8-9$ & $7-8$ & 0 & $3-4$ & 1 & $1-2$ & $1-2$ \\
\hline Salgirszkij & 7 & 4 & 6 & 4 & 7 & 7 & 0 & 2 & $1-2$ & 2 & 2 \\
\hline San Castrese & $7-8$ & $4-5$ & $7-8$ & $5-6$ & $7-8$ & $7-8$ & 0 & $1-2$ & $2-3$ & 2 & $1-2$ \\
\hline Sansin & 7 & 4 & 7 & 5 & 7 & 7 & 0 & $2-3$ & 2 & 2 & 2 \\
\hline Sartilega & $6-7$ & 4 & 7 & 5 & 7 & 7 & 0 & 2 & $2-3$ & 2 & 2 \\
\hline Satani & 7 & $4-5$ & 7 & 5 & $7-8$ & $6-7$ & $0-1$ & 2 & 2 & $1-2$ & 2 \\
\hline Saturn & 7 & 4 & $6-7$ & $5-6$ & $7-8$ & 7 & 0 & 2 & $2-3$ & 2 & $1-2$ \\
\hline Screará & $6-7$ & 4 & $6-7$ & $4-5$ & 7 & $6-7$ & 0 & $1-2$ & 2 & 2 & 2 \\
\hline Schöne von Randon & 6 & $3-4$ & $6-7$ & $4-5$ & 7 & $6-7$ & 0 & 2 & $1-2$ & $1-2$ & 2 \\
\hline Şekerpare & $7-8$ & $4-5$ & $7-8$ & 5 & $8-9$ & $8-9$ & 0 & $1-2$ & $2-3$ & $1-2$ & 2 \\
\hline Selena & $6-7$ & 4 & $6-7$ & 5 & $7-8$ & $8-9$ & 0 & $2-3$ & 2 & $2-3$ & 3 \\
\hline Selyembarack & $6-7$ & $4-5$ & $6-7$ & $4-5$ & 7 & $7-8$ & 0 & $2-3$ & 2 & 2 & 3 \\
\hline Shakar para & $7-8$ & 4 & 7 & 5 & $8-9$ & 9 & 0 & $1-2$ & 2 & 2 & $1-2$ \\
\hline Shastomi & 7 & 4 & $6-7$ & 5 & $7-8$ & $8-9$ & 0 & 2 & 2 & 2 & 1 \\
\hline Sindahlan & $6-7$ & 4 & 7 & $5-6$ & 8 & $7-8$ & 0 & 2 & $2-3$ & $1-2$ & $1-2$ \\
\hline Sindalan & 7 & 4 & $6-7$ & $5-6$ & $7-8$ & 7 & $0-1$ & $1-2$ & 2 & 2 & 2 \\
\hline Sing (sibirica) & $5-6$ & $3-4$ & $5-6$ & 4 & 7 & 6 & 0 & 2 & 1 & $1-2$ & 2 \\
\hline Sirazszkij belüj & 7 & 4 & 7 & 5 & $8-9$ & 7 & 0 & 2 & 2 & $1-2$ & $1-2$ \\
\hline Sirazszkij pozudni & 7 & 4 & 7 & 5 & $8-9$ & 7 & 0 & 2 & $1-2$ & 2 & 2 \\
\hline Sirena & $6-7$ & $3-4$ & $6-7$ & $4-5$ & $7-8$ & $6-7$ & 0 & 3 & 2 & 2 & 2 \\
\hline Soganci & 7 & 4 & 6 & 5 & 8 & 7 & 0 & $1-2$ & 2 & 2 & 2 \\
\hline Sortilege & 6 & 4 & $6-7$ & $4-5$ & 7 & 6 & 0 & 2 & 2 & $1-2$ & 2 \\
\hline Southwick & 6 & 4 & 6 & $5-6$ & $7-8$ & $6-7$ & 0 & $2-3$ & 2 & 2 & 2 \\
\hline Spitak & 7 & 4 & $6-7$ & 5 & 8 & 7 & 0 & 2 & $1-2$ & 2 & 1 \\
\hline Stark Early Orange & 6 & 4 & 6 & $5-6$ & $7-8$ & $6-7$ & 0 & 2 & 2 & 1 & 1 \\
\hline Stella & $6-7$ & 4 & 6 & 5 & 5 & 6 & 0 & $1-2$ & 2 & 1 & $1-2$ \\
\hline Story & 6 & 4 & 6 & $4-5$ & 7 & $6-7$ & 0 & $2-3$ & 2 & 2 & $2-3$ \\
\hline Sun Glo & 6 & 4 & $6-7$ & $5-6$ & 7 & $6-7$ & 0 & $1-2$ & $1-2$ & $1-2$ & 2 \\
\hline Sulmona & $7-8$ & 4 & 7 & 5 & $8-9$ & $8-9$ & 0 & $1-2$ & $2-3$ & 3 & 3 \\
\hline Sundrop & 6 & $3-4$ & 6 & $4-5$ & 7 & $6-7$ & 0 & $1-2$ & 2 & 2 & 2 \\
\hline Supergold & 6 & $3-4$ & 6 & $4-5$ & 7 & $6-7$ & 0 & 2 & 2 & $1-2$ & 2 \\
\hline Szacer & 7 & 4 & 6 & 5 & 7 & 7 & 0 & 3 & 1 & 2 & $1-2$ \\
\hline Szaharnüj Goluba & $6-7$ & $4-5$ & 6 & 5 & 8 & $6-7$ & 0 & 2 & $1-2$ & $1-2$ & $1-2$ \\
\hline Szalgirszkij & 6 & 4 & 6 & 5 & 8 & $6-7$ & 0 & 2 & $1-2$ & 2 & 2 \\
\hline
\end{tabular}




\begin{tabular}{|c|c|c|c|c|c|c|c|c|c|c|c|}
\hline Cultivar & TB & WB & $\mathrm{RB}$ & NB & LB & $\mathrm{KB}$ & SB & $\mathrm{OP}$ & FR & SS & DR \\
\hline Szamarkandszkij rannij & 6 & 4 & 7 & $5-6$ & $7-8$ & 8 & 0 & 2 & 2 & $1-2$ & 3 \\
\hline Szegedi maumut & $6-7$ & $3-4$ & $6-7$ & 4 & $7-8$ & 7 & 0 & $2-3$ & 2 & 2 & 2 \\
\hline Szentrjabszkij urjuk & $5-6$ & $4-5$ & 7 & 5 & 7 & 7 & 0 & 2 & 1 & $1-2$ & 1 \\
\hline Szilisztrai & $6-7$ & 4 & $6-7$ & 5 & $7-8$ & 7 & 0 & 2 & 2 & 2 & $1-2$ \\
\hline Szilisztrenszka kompotna & $6-7$ & 4 & $6-7$ & $5-6$ & $7-8$ & 7 & 0 & $1-2$ & 2 & 2 & 2 \\
\hline Sziriai kajszi & $7-8$ & $4-5$ & 7 & 5 & 9 & 8 & 0 & 2 & 3 & 2 & 2 \\
\hline Szkopszka krupna & $6-7$ & $3-4$ & $6-7$ & 5 & $7-8$ & 7 & 0 & 2 & 2 & 2 & 3 \\
\hline Szmena & 6 & $3-4$ & $6-7$ & $4-5$ & $7-8$ & $6-7$ & 0 & $2-3$ & 2 & 2 & 2 \\
\hline Szorocsinszkij & 6 & $3-4$ & 6 & $4-5$ & 7 & $6-7$ & 0 & 2 & 2 & 2 & $1-2$ \\
\hline Szőregi cukorrózsa & 6 & $3-4$ & $6-7$ & 4 & 7 & 7 & 0 & 2 & 2 & 2 & 2 \\
\hline Szpitak & 6 & 4 & 7 & 5 & 8 & $5-7$ & $0-1$ & 2 & $1-2$ & $1-2$ & $1-2$ \\
\hline Szuper rózsa H-II. 36/26 & 6 & $3-4$ & $6-7$ & $4-5$ & 7 & 7 & 0 & $1-2$ & $1-2$ & 3 & 2 \\
\hline Szuphoni & 7 & $4-5$ & 7 & 4 & $7-8$ & $6-7$ & 0 & $1-2$ & 1 & $1-2$ & $1-2$ \\
\hline Tabarsa & 7 & 4 & $6-7$ & 5 & 7 & 7 & 0 & 2 & $1-2$ & $1-2$ & 2 \\
\hline Tadeo & 7 & 4 & $5-6$ & 5 & 8 & 7 & 0 & $2-3$ & $2-3$ & 2 & 2 \\
\hline Tápiószelei korai & 6 & $3-4$ & $6-7$ & 4 & 7 & $6-7$ & 0 & 2 & $1-2$ & 2 & 2 \\
\hline Tardicot & $6-7$ & 4 & $6-7$ & $5-6$ & $7-8$ & $6-7$ & 0 & $1-2$ & 2 & 2 & 2 \\
\hline Tardif de Tain & $6-7$ & 4 & $6-7$ & $5-6$ & $7-8$ & $6-7$ & 0 & 2 & 2 & 2 & 2 \\
\hline Tegnamus & $6-7$ & 4 & 6 & 5 & 7 & 7 & 0 & $2-3$ & $2-3$ & 2 & 2 \\
\hline Tengeribarack C. 809 & 6 & $3-4$ & $6-7$ & 4 & 7 & 6 & 0 & 1 & 2 & $1-2$ & $1-2$ \\
\hline Tengeribarack C. 1300 & 6 & $3-4$ & $6-7$ & $4-5$ & 7 & 6 & 0 & $1-2$ & 2 & 2 & 2 \\
\hline Tengeribarack C. 1650 & 6 & $3-4$ & $6-7$ & 4 & 7 & 6 & 0 & 1 & 2 & $1-2$ & 2 \\
\hline Tengeribarack C. 1652 & 6 & $3-4$ & $6-7$ & 5 & 7 & 6 & 0 & 1 & 2 & $1-2$ & $1-2$ \\
\hline Tengeribarack C. 2546 & 6 & $3-4$ & $6-7$ & 4 & $7-8$ & $6-7$ & 0 & 2 & $2-3$ & 2 & $2-3$ \\
\hline Tilton & $6-7$ & $3-4$ & $6-7$ & 5 & $7-8$ & 7 & 0 & $2-3$ & $2-3$ & 2 & 2 \\
\hline Tirynthos & $7-8$ & $4-5$ & 7 & 5 & 7 & 8 & 0 & 2 & $2-3$ & 1 & $1-2$ \\
\hline Tirziu de Bucuresti & $6-7$ & 4 & $6-7$ & $5-6$ & $7-8$ & 7 & 0 & 2 & $1-2$ & 2 & 2 \\
\hline Tlor-Ciran & 7 & $4-5$ & 7 & 5 & $8-9$ & 7 & 0 & 1 & 2 & 1 & $1-2$ \\
\hline Tokaloglu-Erzincan & $7-8$ & $4-5$ & $7-8$ & 5 & 8 & $7-8$ & 0 & 2 & $2-3$ & 2 & 1 \\
\hline Tokaloglu-Konya Eregli & $7-8$ & $4-5$ & $7-8$ & 5 & 8 & $7-8$ & 0 & 2 & 2 & 2 & 2 \\
\hline Tokaloglu-Yalova & $7-8$ & $4-5$ & $7-8$ & 5 & 8 & $7-8$ & 0 & 2 & 2 & $1-2$ & 2 \\
\hline Tola (sibiririca) & $5-6$ & $3-4$ & 6 & 4 & 7 & $5-6$ & 0 & 2 & 1 & 1 & 2 \\
\hline Touursi Alberge & $6-7$ & $3-4$ & $6-7$ & $5-6$ & 7 & 6 & 0 & 1 & $1-2$ & 2 & 2 \\
\hline Toyaco & $6-7$ & $3-4$ & $6-7$ & $4-5$ & $7-8$ & 7 & 0 & 1 & 2 & 2 & $1-2$ \\
\hline Toyesi & $6-7$ & $3-4$ & $6-7$ & $4-5$ & $7-8$ & 7 & 0 & $2-3$ & 2 & 2 & 2 \\
\hline Toyuda & $6-7$ & $3-4$ & $6-7$ & $4-5$ & $7-8$ & 7 & 0 & 1 & 2 & 2 & 2 \\
\hline Traian & $6-7$ & $3-4$ & $6-7$ & $4-5$ & $7-8$ & 7 & 0 & 2 & 2 & 2 & 2 \\
\hline Trewatt & $6-7$ & 4 & 6 & $5-6$ & $7-8$ & 6 & 0 & 2 & 3 & 2 & 2 \\
\hline Triumph von Trier & 6 & $3-4$ & 6 & $4-5$ & 7 & $5-6$ & 0 & 1 & 2 & 2 & 2 \\
\hline Tsunami & $6-7$ & 4 & $6-7$ & $5-6$ & 8 & $6-7$ & 0 & $2-3$ & 2 & 1 & 1 \\
\hline Tufanda Izmir & $7-8$ & $4-5$ & 7 & 5 & 8 & $7-8$ & 0 & 2 & 3 & 2 & $1-2$ \\
\hline Tuhum-sansz & 7 & 4 & 7 & 5 & $7-8$ & 7 & $0-1$ & 2 & 2 & 2 & 2 \\
\hline Turdi-kuli & $7-8$ & $4-5$ & $6-7$ & $4-5$ & $8-9$ & 7 & 0 & $2-3$ & 1 & 1 & 2 \\
\hline Ungarische Beste & $6-7$ & $3-4$ & $6-7$ & $4-5$ & $7-8$ & $6-7$ & 0 & $1-2$ & 2 & 2 & 1 \\
\hline Urjuko-alücsa zsoltaja & $5-6$ & 4 & 7 & 5 & 8 & $6-7$ & 0 & $1-2$ & 1 & 1 & 2 \\
\hline Uspeh & $5-6$ & $3-4$ & 7 & $4-5$ & $7-8$ & $6-7$ & 0 & 2 & 2 & 2 & $1-2$ \\
\hline Utah & 6 & $3-4$ & 6 & 5 & 7 & 6 & 0 & 2 & 2 & 2 & 2 \\
\hline
\end{tabular}




\begin{tabular}{|c|c|c|c|c|c|c|c|c|c|c|c|}
\hline Cultivar & $\mathrm{TB}$ & WB & $\mathrm{RB}$ & NB & LB & $\mathrm{KB}$ & SB & OP & FR & SS & DR \\
\hline Üllőii csúcsos & $6-7$ & 4 & $6-7$ & $4-5$ & 7 & $6-7$ & 0 & $2-3$ & 2 & 2 & $1-2$ \\
\hline Valenciano & $7-8$ & 4 & $6-7$ & 5 & 8 & 7 & 0 & $2-3$ & $2-3$ & $1-2$ & $1-2$ \\
\hline Valnur & $6-7$ & 4 & $6-7$ & 5 & $7-8$ & $6-7$ & 0 & 2 & 2 & 2 & 2 \\
\hline Vászonbarack & $6-7$ & $4-5$ & $6-7$ & $4-5$ & 7 & $6-7$ & 0 & 3 & 2 & 2 & $2-3$ \\
\hline Veecot & 6 & $3-4$ & 6 & $4-5$ & 8 & 6 & 0 & $2-3$ & 2 & $1-2$ & 3 \\
\hline Vegama & $6-7$ & 4 & $6-7$ & $5-6$ & $7-8$ & 7 & 0 & 2 & $2-3$ & 2 & 2 \\
\hline Velasquez Fino & $7-8$ & $4-5$ & 7 & 5 & $8-9$ & $7-8$ & 0 & $1-2$ & 3 & $2-3$ & 2 \\
\hline Velita & 7 & $3-4$ & $6-7$ & 5 & $7-8$ & 7 & 0 & 2 & 2 & 2 & 2 \\
\hline Velvaglo & 7 & $3-4$ & 7 & 5 & $7-8$ & $6-7$ & 0 & $2-3$ & $2-3$ & 2 & 3 \\
\hline Vemina & 7 & $3-4$ & 6 & $4-5$ & 7 & $6-7$ & 0 & 2 & $1-2$ & 2 & $1-2$ \\
\hline Venus & 7 & $3-4$ & $6-7$ & $5-6$ & $7-8$ & $6-7$ & 0 & 2 & 2 & 2 & 2 \\
\hline Versaillesi & $6-7$ & $3-4$ & $6-7$ & $5-6$ & 7 & 6 & 0 & 2 & $1-2$ & 2 & 2 \\
\hline Vestar & $6-7$ & $3-4$ & $6-7$ & $5-6$ & 7 & 6 & 0 & 2 & $2-3$ & 2 & 2 \\
\hline Viceroy & 8 & 4 & 7 & 5 & $7-8$ & $6-7$ & 0 & 2 & 2 & 2 & 2 \\
\hline Vivagold & 8 & 4 & 6 & $5-6$ & $7-8$ & 6 & 0 & 2 & 2 & 2 & $1-2$ \\
\hline Voronyezsi & $5-6$ & $3-4$ & 6 & 4 & 7 & $5-6$ & 0 & 2 & 1 & $1-2$ & 1 \\
\hline Vulcan & $6-7$ & 4 & $6-7$ & 5 & 8 & $6-7$ & 0 & $1-2$ & 3 & 2 & 2 \\
\hline Watkins & 6 & $3-4$ & $6-7$ & $5-6$ & 7 & 6 & 0 & 2 & 2 & $2-3$ & 2 \\
\hline Westley & 6 & 4 & 6 & $5-6$ & 7 & 6 & 0 & 2 & $2-3$ & 2 & 2 \\
\hline White Silver & 6 & $3-4$ & 6 & 6 & 7 & $5-6$ & 0 & $2-3$ & 2 & $2-3$ & 1.2 \\
\hline Wondercot & 7 & 4 & 7 & $5-6$ & 7 & 7 & 0 & $2-3$ & 2 & 1 & 2 \\
\hline Yakamine & 6 & $3-4$ & $6-7$ & $5-6$ & $7-8$ & $6-7$ & 0 & 2 & 2 & $1-2$ & $1-2$ \\
\hline Yellowcot & 6 & 4 & $6-7$ & $5-6$ & $7-8$ & 7 & 0 & 2 & 2 & $2-3$ & 2 \\
\hline Ying ji-sha & $6-7$ & $4-5$ & 6 & 6 & 8 & $7-8$ & 0 & $1-2$ & 2 & 2 & $1-2$ \\
\hline Zaposzdole & 6 & $3-4$ & 6 & 5 & 7 & 6 & $0-1$ & 2 & 1 & 1 & 1 \\
\hline Zard & $5-6$ & 3 & $5-6$ & 5 & 9 & 7 & 0 & 2 & 1 & 1 & 1 \\
\hline Zarolju & $5-6$ & $3-4$ & $5-6$ & $4-5$ & $7-8$ & 5 & $0-1$ & 2 & 2 & 2 & $1-2$ \\
\hline Zolotoje leto & 6 & 4 & 6 & $4-5$ & $7-8$ & 6 & 0 & $2-3$ & 2 & 2 & 2 \\
\hline
\end{tabular}

Table 2: Relative ecological indicator values of apricot cultivars

\begin{tabular}{|l|c|c|c|}
\hline \multicolumn{1}{|c|}{$\begin{array}{c}\text { Relative ecological } \\
\text { indicators }\end{array}$} & Interval & Mean & CV, \% \\
\hline Temperature figures (TB) & $5 \rightarrow 8$ & $6,56 \pm 0,81$ & 12,3 \\
\hline Moisture figures(WB) & $3 \rightarrow 5$ & $3,64 \pm 0,69$ & 18,1 \\
\hline Reaction figures (RB) & $5 \rightarrow 7$ & $6,41 \pm 0,34$ & 5,3 \\
\hline Nitrogen figures (NB) & $4 \rightarrow 6$ & $4,84 \pm 0,82$ & 16,9 \\
\hline Light figures (LB) & $7 \rightarrow 9$ & $7,55 \pm 0,74$ & 9,9 \\
\hline $\begin{array}{l}\text { Continentality values } \\
\text { KB) }\end{array}$ & $5 \rightarrow 8$ & $6,65 \pm 0,89$ & 13,6 \\
\hline Salt figures (SB) & $0 \rightarrow 1$ & $0,03 \pm 0,04$ & 135,3 \\
\hline Open pollination (OP) & $1 \rightarrow 4$ & $1,99 \pm 0,71$ & 35,8 \\
\hline Frost resistance (FR) & $1 \rightarrow 3$ & $1,94 \pm 0,69$ & 36,1 \\
\hline Sharka sensitivity (SS) & $1 \rightarrow 3$ & $1,79 \pm 0,56$ & 31,3 \\
\hline Disease resistance (DR) & $1 \rightarrow 3$ & $1,74 \pm 0,63$ & 36,0 \\
\hline
\end{tabular}

Table 3: Comparison of ecological and biological indicator values on two fruit species

(The plums were in Intern. J. Hort. Sci. 2015)

\begin{tabular}{|c|c|c|c|}
\hline $\begin{array}{c}\text { Indicator values } \\
\text { (means) }\end{array}$ & Plums & Apricots & Differences, \% \\
\hline TB & 5.79 & 6.55 & $88.4^{\circ}$ \\
\hline $\mathrm{WB}$ & 5.56 & 3.64 & $152.7^{* *}$ \\
\hline $\mathrm{RB}$ & 5.48 & 6.41 & $85.5^{\circ}$ \\
\hline $\mathrm{NB}$ & 5.17 & 4.84 & 106.8 \\
\hline $\mathrm{LB}$ & 5.57 & 7.55 & 73.8 \\
\hline $\mathrm{KB}$ & 5.83 & 6.55 & $89.0^{\circ}$ \\
\hline $\mathrm{SB}$ & 0.04 & 0.03 & $133.3^{*}$ \\
\hline $\mathrm{OP}$ & 2.62 & 1.99 & $131.7^{*}$ \\
\hline $\mathrm{FR}$ & 1.84 & 1.94 & 94.8 \\
\hline $\mathrm{SS}$ & 1.96 & 1.79 & 109.5 \\
\hline $\mathrm{DR}$ & 1.88 & 1.74 & 108.0 \\
\hline
\end{tabular}




\section{References}

Bordeianu, T. - Constantinescu, N. - Stefan, N. (1967): Caisul persicul. Pomol. Rep. Soc. Rom. V. - Edit. Acad. Rep. Soc. Rom., Bucuresti.

Bordeianu, T. - Constantinescu, A. - Stefan, N. (1969): Soiuri noi si hibridi de perspetiva. Pomol. Rep. Soc. Rom. VIII. - Edit. Acad. Rep. Soc. Rom., Bucuresti.

Borhidi A. (1969): Adatok a kocsánytalan tölgy (Quercus petraea fajcsoport) és a molyhos tölgy (Quercus pubescens fajcsopoort) kistájainak ökológiai-cönológiai magatartásához. Bot. Közlem. 56: 155-158.

Borhidi A. (1993): A magyar flóra sociális magatartástípusai, természetességi és relatív ökológiai értékszámai. KTM Term. véd. Hiv. Janus Pann. Tud. Egy., Pécs.

Borhidi A. (1995): Social behaviour types, the naturalness and relative ecological indicator values of the higher plants in the Hungarian flora. Acta Bot. Hung. 39: 97-181.

Brooks, R. M. - Olmo, H. P. (1972): Register of mew fruit and nut varieties. Second edition. Univ. Calif. Press, Berkeley - Los Angeles - London.

Brózik, S. (1960): Csonthéjas gyümölcsüek: Szilva, kajszi. Mezögazdasági Kiadó, Bp.

Brózik, S. - Nyéki, J. (1975): Gyümölcstermő növények termékenyülése. Mezőgazdasági Kiadó, Bp.

Cociu, V. (1993): Caisul. Edit. Ceres, Bucuresti.

Crane, M. B. - Lawrence, W. J. C. (1956): The genetics of garden plants. MacMillan Co. Press, London.

Crossa-Raynaud, P. H. (1977): L'acclimation des vaietes fruitiers. Ann. Amel. Plant. 27: 497-507.

Ellenberg, H. (1950): Landwirtschaftliche Pflanzensoziologie I. Unkrautgemeinschaften als Zeiger für Klima und Boden. Ulmer Verlag, Stuttgart.

Ellenberg, H. (1952): Landwirtschaftliche Pflanzensoziologie II. Wiesen und Weiden und ihre standortliche Bewertung. Ulmer Verlag, Stuttgart.

Ellenberg, H. (1963): Ökologische Beiträge zur Umweltgestaltung. Ulmer Verlag, Stuttgart.

Ellenberg, H. (1974): Zeigerwerte der Gefasspflanzen Mitteleuropas. Scripta Geobot. IX. Goltze Verlag, Göttingen.

Ellenberg, H. - Weber, H. E. - Düll, R. -Wirth, W. - Werner, W. - Paulissen, D. (1991): Zeigeiwerte von Pflanzen in Mitteleuropa. Scripta Geobot. XVIII. Goltze Verlag, Göttingen.

Entz, F. (1857-1859): Kertészeti Füzetek I-15 füz. Herz J., Pest.

Faust, M. (1989): Physiology of temperate zone fruit trees. J. Wiley and Sons, New York - Chichester - Brisbane - Toronto Singapure.

Faust, M. - Surányi, D. - Nyujtó F. (1998): Origin and dissemination of apricot. Hort. Rev. N. Y. 20:

Faust, M. - Surányi, D. - Gradziel, T. - Timon, B. - Nyujtó, F. (edit. Janick, J.) (2011): Origin and dissemination of Prunus. Scripta Horticult. 11: 1-241.

Fideghelli, C. - Monstra, F. (1977): Monografia di cultivars di albicocco. Inst. Speriment Roma.

Gardner, V. R. - Bradford, F. Ch. - Hooker, H. D. Jr. (1952): The fundamentals of fruit production. McGraw-Hill Book Co., New York - Toronto - London.
G. Tóth, M. (1997): Gyümölcsészet. Primom Váll. Alap., Nyíregyháza.

Gyuró, F. (edit.) (1974): A gyümölcstermesztés alapjai. Mezőgazdasági Kiadó, Bp.

Gyuró, F. (edit.) (1990): Gyümölcstermesztés. Mezőgazdasági Kiadó, Bp.

Hedrick, U. P. (1938): Cyclopedia of hardy fruits. MacMillan Co., New York.

Iszakova, M. D. 1988: Apricot varieties for the European part of the USSR. Acta Hort. Hague 209: 29-32.

Iversen, J. (1936): Biologische Pflanzentypen als Hilfsmittel in der Vegetationsforschung. Levin und Munksgaard, Kopenhagen. 224.

Jávorka, S. - Soó, R. (1951): A magyar növényvilág kézikönyve I-II. Akadémiai Kiadó, Bp.

Kárpáti, I. (1978): Magyarországi vizek és ártéri szintek növényfajainak ökológiai besorolása. Keszth. Agrártud. Egy. Kiadv. 20: 5-62.

Kárpáti, Z. - Terpó, A. (1971): Alkalmazott növényföldrajz. Mezőgazdasági Kiadó, Bp.

Knight, R. L. (1969): Abstract bibliograhy of fruit breeding and genetics to 1965. Prunus. Comm. Agric. Bur. (CAB), East Malling.

Kobel, F. (1954): Lehrbuch des Obstbaus auf phsiologischer Grundlage. Springer Verlag, Berlin.

Kosztina, K. F. (1936): Abrikosz. Izd. Vaszhnyil, Leningrad.

Kosztina, K. F. (1964): Application of the botanico-geographical method to classification of apricot. 150 let Goszud. Nyikitsz. Bot. Szada Jalta. p. 170-189.

Kovács, J. A. (1979): Indicatorii biologici, ecologici si economici ai florei pajistilor. Minist. Agricult. si Ind. Aliment., Bucuresti.

Kozma, P. - Nyéki, J. - Soltész, M. - Szabó, Z. (2003): Floral biology, pollination and fertilisation in temperate zone fruit species and grape. Akadémiai Kiadó, Bp.

Krüssmann, G. (1978): Handbuch der Laubgehölze Band III. Verlag P. Parey, Berlin- Hamburg.

Larcher, W. (1980): Physiological plant ecology. Springer Verlag, Berlin - Heidelberg - New York.

Löschnig, J. - Passecker, F. (1954): Die Marille und ihre Kultur. Öst. Agrarverlag, Wien.

Mándy Gy. (1963): Kertészeti növények nemesítése táblázatokban. Mezőgazdasági Kiadó, Bp.

Martinez-Gomez, P. - Dicenta, F. - Audergon, J. M. (2000): Behaviour of apricot (Prunus armeniaca L.) cultivars in the presence of sharka (plum pox potyvirus): a review. Agronomie 20: 407-422.

McGregor, S. E. (1976): Insect pollination of cultivated crop plants. U.S. Dept. Agric., Washington.

Mehlenberger, A. - Cociu, V. - Hough, F. (1992): Apricots. in: Genetic resources of temperate fruit and nut crops I-II. ISHS, Wageningen. p. 85-107.

Meusel, H. - Schubert, R. (1972): Volk und Wissen. Akademie Verlag, Berlin

Nyéki, J. (szerk.) (1980): Gyümölcsfajták virágzásbiológiája és termékenyülése. Mezőgazdasági Kiadó, Bp.

Nyéki, K. - Soltész, M. (edit.) (1996): Floral biology of temperate zone fruit trees and small fruits. Akadémiai Kiadó, Bp.

Nyéki, J. - Soltész, M. - Szabó, Z. (2012): Minőségi szilvatermesztés. DE AGTC, Kertészeti Intézet, Debrecen. 
Nyujtó F. - Surányi D. (1981): Kajszibarack. Mezőgazdasági Kiadó, Bp.

Nyujtó F. - Tomcsányi P. (1959): A kajszibarack és termesztése. Mezőgazdasági Kiadó, Bp.

Odier, G. (1978): Role du nayonnement solaire en arboriculture fruitière. L'Arboric. Fruit. 295: 23-29.

Papp J. (szerk.) (2003): 1. Gyümölcstermesztési alapismeretek. mezőgazda Kiadó, Bp.

Papp J. (szerk.) (2004): 2. A gyümölcsök termesztése. Mezőgazda Kiadó, Bp.

Papp, J. - Tamási, J. (1979): Gyümölcsösök talajművelése és tápanyagellátottsága. Mezőgazdasági Kiadó, Bp.

Pénzes B. - Szalay L. (szerk.) (2004): Kajszi. Mezőgazda Kiadó, Bp.

Pernesz Gy. (2016): Nemzeti fajtajegyzék - National list of varieties. Gyümölcs - Fruit. NÉBIH, Bp. ISSN 1585-8308.

Pichler, F. - Karrer, G. (1991): Comparison of different ecological indicator value systems.in: Horváth, F.(edit.): Poster Abstracts 34th IAVS Symposium, Eger, Hungary.p. 102-104.

Porpáczy A. (edit.) (1964): A korszerü gyümölcstermesztés elméleti kérdései. Mezőgazdasági Kiadó, Bp.

Roach, F. A. (1985): Cultivated fruits of Britain. Their origin and history. Basil Blackwill Public. Ltd., Oxford-New York.

Précsényi, I. (1986): The acoluthic space and its importance in the ecologicai research. Acta Bot. Hung. 32: 53-60.

Scherfose, V. (1990): Salz-Zeigerwerte von Gefásspflanzen der Salzmarschen Tideröhrichte und Salzwassertümpel an der deutschen Nord- und Ostseeküste. Jb. Nieders. Landesamt Wasser und Abfall, Forsch. stelle Küste 39: 31-82

Schwanitz, (1973): A kultúrnövények keletkezése: az egész növényvilág evolúciós modellje.Mezőgazdasági Kiadó, Bp.

Simon, T. (1988): A hazai edényes flóra természetvédelmi értékbesorolása. Abstr. Bot. 2: 1-23.

Simon, T. (1991): A magyarországi edényes flóra határozója (Harasztok - Virágos növények). Nemzeti Tankönyvkiadó, Bp.

Soltész, M. (edit.) (1998): Gyümölcsfajta-ismeret és-használat. Mezőgazda Kiadó, Bp.

Soltész, M. (szerk.) (2014): Magyar Gyümölcsfajták. Mezőgazda Kiadó, Bp.

Soó, R. (1964-1985): A magyar flóra és vegetáció rendszertaninövényföldrajzi kézikönyve I-VII. köt. Akadémiai Kiadó, Bp.

Soriano, J. M. - Vera-Ruiz, E. M. - Vilanova, S., MartínezCalvo, J. - Llácer, J. - Badenes, M. L. - Romero, C. (2008): Identification and mapping of a locus conferring plum pox virus resistance in two apricot-improved linkage maps. Tree Genetics \& Genomes 4: 391-402.

Surányi D. (1985): Kerti növények regénye. Mezőgazdasági Kiadó, Bp.

Surányi, D. (1991-2015): Fenológiai naplók (kézirat). Gyümölcskut. Áll. Kft, Cegléd.
Surányi, D. (2000): A termesztett gyümölcsfajok- és fajták ökológiai sajátosságai, azok besorolása a Simon-féle értékszámok szerint. Acta Biologica Debrecina 11 (1): 143.

Surányi, D. (2002): Gyümölcsöző sokféleség (Biodiverzitás a gyümölcstermesztésben). Akcident Kft., Cegléd.

Surányi, D. (2006): Magyarország gyümölcs-flórájának biológiaiökológiai jellemzése (Hazai vadon termö, meghonosodott, elvadult és potenciális gyümölcsfajok, valamint termesztett gyümölcsfajták értékelése). Kanitzia 14: 137-206.

Surányi, D. (2009): Lépcsőfokok - Értekezések a gyümölcstermesztés köréböl. GyDKFI, Cegléd.

Surányi, D. (2011): A sárgabarack, Armeniaca vulgaris Lam. Szent István Egyetem Kiadó, Gödöllő.

Surányi, D. (2014): Relative ecological indicators of the registrated and old historical fruit cultivars in Hungary. Acta Bot. Hung. 56 (34): 433-484.

Surányi, D. (2015): Relative ecological and biological indicator values of plum and prune cultivars. Inter. J. Hort. Sci. 21 (3-4): 37-53.

Szalay L. - Surányi D. - †Nyujtó F. (2011): A sárgabarack fontosabb termesztett fajtái. in: Surányi, D. 2011: A sárgabarack, $A r-$ meniaca vulgaris Lam. Szent István Egyetem Kiadó, Gödöllő. p. 254-272.

Szmükov, V. K. (1974-1975): Kul'tura abrikosza v neorosaemüh uszlovijah Moldavii I-II. Izdat. Stiinca. Kisinyev.

Terpó, A. (1974): Gyümölcstermő növényeink rendszertana és földrajza. in: Gyúró, F. (ed.) A gyümölcstermesztés alapjai. Mezőgazdasági Kiadó, Bp. p.139-219.

Tomcsány P. (1960): Gyümölcsfajták irodalmi vonatkozásai (témadok.). Agroinform, Bp.

Tomcsányi P. (edit.) (1979): Gyümölcsfajtáink. Gyakorlati pomológia. Mezőgazdasági Kiadó, Bp.

Tüxen, R., Ellenberg, H. (1937): Die systematische und ökologische Gruppenwer. Mitt. flor.-soz. Arbeuitsgem. Niedersachsen 3: 171-184.

V. Németh, M. (1986): The virus, mycoplasma and rickettsia diseases of fruit trees. Akadémiai Kiadó, Bp.

Zhebentyayeva, T. N. - Reighard, G. L. - Lalli, D. - Gorina, V.M. - Krška, B. - Abbott, A. G. (2008): Origin of resistance to plum pox virus in apricot: what new AFLP and targeted SSR data analyses tell. Tree Genetics \& Genomes 4: 403-417.

Zólyomi B. (1964): Methode zur ökologischen Characterisierung der Vegetation seinheiten und zum Vergleich der Standorte. Mathematisch-statistische Bearbeitung der Beispiele von I. Précsényi. Acta Bot. Hung. 10: 377-416.

Zólyomi B. (1987): Coenotone, ecotone and their role in the preservation of relic species. Acta Bot. Hung. 33: 3-18.

Zólyomi, B. - Baráth, Z. - Fekete, G. - Jakucs, P. - Kárpáti, I. - Kárpáti, V. - Kovács, M. - Máthé, I. (1967): Einreihung von 1400 Arten der ungarischen Flora in ökologischen Gruppen nach TWR-Zahlen. Fragmenta Bot. Mus. Hist. Nat. Hung. 4: 101-142. 